\title{
Celestina: Documento bibliográfico (suplemento número 41)
}

\author{
Amaranta Saguar García \\ Universidad Complutense de Madrid \\ Devid Paolini \\ The City College of New York
}

2602. ACIERNO, ALYSSA, «From Quest to Brothel: The Demise of the Courtly Love Tradition in La Celestina», IAFOR Journal of Arts \& Humanities 4.1 (2017): 16-22 [en línea, <https://iafor.org/journal/iaforjournal-of-arts-and-humanities/volume-4-issue-1/article-2 $>$, fecha de consulta: 13 de septiembre de 2019].

El autor de LC comparte el código del amor cortés con sus lectores y utiliza esta comunidad para transmitir significados en su obra. El contexto cortés es evidente en el lenguaje y en las situaciones de la obra que afectan a los personajes principales, pero muy pronto se traslada igualmente a los personajes no corteses, introduciendo nuevas connotaciones: el significado del lenguaje y de los actos corteses se pone en duda, se relativiza, y sirve para oponer sistemas de valores completamente diferentes. En concreto, se opone el modelo idealizado del amor cortés a un modelo más realista, basado en las necesidades de la vida diaria, el interés y el provecho [adaptación del resumen de la autora].

2603. AGUILAR PERDOMO, María del Rosario, "La Celestina». En Des jardins \& des libres, dir. Michaël Jakob. Genève: Metis Presses, 2018, 166-167.

Entrada de catálogo sobre el ejemplar único de la edición de Toledo 1500 de la Comedia, conservado en la biblioteca de la fundación Martin Bodmer.

2604. AIMO, Laura, ed., Trame: "Celestina laggiù vicino alle concerie in riva al fiume» per la regia di Luca Ronconi. Milano: EDUCatt, 2016.

Librito dedicado al director escénico Luca Ronconi, responsable del montaje Celestina laggiù vicino alle concerie in riva al fiume de 2014, que 
recoge algunos de los temas, las hipótesis y las interpretaciones que se pronunciaron en el encuentro "Da de Rojas a Garneau attraverso Gadda: la Celestina», celebrado en Milán el 27 de febrero de 2014. Reúne puntos de vista de importantes críticos e intelectuales italianos, como Claudio Bernardi, Roberta Carpani, Giuseppe Lupo, Giuseppe Mazzocchi e Paola Ventrone.

2605. ALBALÁ PELEGRÍN, Marta, "Converso Migration and Social Stratification: Textual Representations of the Marrano from Iberia to Rome, 1480-1550». En Exile and Religious Identity, 1500-1800, eds. Jesse Spohnholz y Gary K. Waite. London: Pickering and Chatto Publishers, 2014, 141-156.

Capítulo de libro que explora la producción literaria romana en la que se describen las especiales habilidades y picaresca gracias a las cuales los judíos y conversos asentados en Roma después del decreto de expulsión de 1492 sobreviven en la ciudad. Esta literatura hace visibles los desplazamientos del significado del concepto de "converso" dentro de la sociedad romana, así como del de "extranjero" [adaptación del resumen de la autora].

2606. ALBUJAR-ESCUREDO, Miguel Ángel, «Anatomía comparada de la representación de la muerte en la literatura española transatlántica durante el ocaso de la Edad Media y el Renacimiento", Ph.D., University of Nebraska, 2017 [en línea, <https://digitalcommons.unl.edu/ modlangdiss/39>, fecha de consulta: 13 de septiembre de 2013].

Comparación diacrónica de obras literarias seleccionadas de entre el canon hispánico medieval y temprano moderno con la finalidad de determinar cómo se representaba la muerte en las épocas correspondientes. Entre esas obras se encuentra $L C$, a la que se dedica por completo el capítulo 3 (pp. 86-170). Resulta especialmente interesante como estado de la cuestión e introducción al tema de la muerte en la obra.

2607. ANDINO SÁNCHEZ, Antonio de Padua, "La originalidad literaria del 'amor de comedias' en Celestina», Colindancias 9 (2018): 129-146. [en línea, <https://colindancias.uvt.ro/index.php/colindancias/article/ view/219/182>, fecha de consulta: 13 de septiembre de 2019]

La vinculación de Celestina con la comedia romana contiene en sí muchas de las más interesantes incógnitas que presenta la obra. Una de ellas, sin duda, es la descripción y desarrollo que la Tragicomedia hace del amor entre sus personajes. En este artículo se insiste en la estrecha relación de Celestina con las fuentes latinas de Plauto y Terencio, y se intenta elucidar el modelo de amor utilizado por Fernando de Rojas en el desarrollo de la trama [resumen del autor]. 
2608. ANDRÉ DE UBACH, Carmen del Pilar, «Perspectivismo y discurso proverbial en los retratos de La Celestina», Letras 77 (2018): 85-96 [en línea, <http://erevistas.uca.edu.ar/index.php/LET/article/view/1712>, fecha de consulta: 13 de septiembre de 2019].

La autora aborda el perspectivismo que se plasma a través de la percepción de los protagonistas por parte de sí mismos y de otros personajes, y lo pone en relación con la aplicación del discurso proverbial para la caracterización y la justificación de las representaciones de los personajes [adaptación del resumen de la autora].

2609. ANDREI, Filippo, "The Tragicomedy of Lament: La Celestina and the Elegiac Legacy of Boccaccio's Fiammetta». En Reconsidering Boccaccio, Medieval Contexts and Global Intertexts, eds. Olivia Holmes y Dana Stewart. Toronto: University of Toronto Press, 2018, 365-402.

El estudioso se enfoca en la influencia de la Fiammetta de Boccaccio en la literatura española del siglo Xv ocupándose, en particular, de la novela sentimental y de $L C$. El análisis llevado a cabo pone en evidencia los numerosos rasgos en común que la obra italiana comparte con el texto de Rojas.

2610. ARAGÜÉS, José, «Ejemplos desiguales. Petrarca-Rojas-Erasmo", en "La razón es Aurora": estudios en homenaje a la profesora Aurora Egido, eds. Á. Ezama et al. Zaragoza: Institución Fernando el Católico, 2017, 267-276, [en línea, <https://ifc.dpz.es/recursos/ publicaciones/36/11/21aragues.pdf $>$, fecha de consulta: 02 de diciembre de 2019].

Tras exponer los principios retóricos clásicos básicos sobre el exemplum e introducir el concepto de los exempla ex maioribus ad minora y su recurrencia en el género de la consolatoria, repasa las reinterpretaciones de este mismo procedimiento de Erasmo (en De copia) y Petrarca (epístola a Felipe de Cabassole) para desembocar en un análisis de la subversión de dicho recurso hacia la mitad del planto de Pleberio. Acaba calificando este pasaje de contrafactum de la epístola petrarquesca y viéndolo como la culminación del proceso de cuestionamiento y relativización del valor ejemplar de este tipo de comparaciones de mayor a menor iniciado por el italiano, gracias al cual Erasmo podría más tarde formular una teoría poética del exemplum que explora las similitudes y las diferencias entre los hombres extraordinarios de los exempla y los hombres corrientes que recurren a ellos.

2611. BARRIO GARCÍA, Alejandra, "Aproximación a un tipo literario a través de su discurso: de Trotaconventos a Celestina». En Estudios de literatura medieval en la Península Ibérica, ed. Carlos Alvar. San Millán de la Cogolla: CILENGUA, 2015, 279-288. 
Análisis del personaje de la alcahueta en el $L B A$ y $L C$ que se centra, en particular, en su habilidad con el lenguaje. Todo eso con el objetivo de señalar la evolución que experimentó de una obra a otra.

2612. BASÁÑNEZ BARRIO, Endika, "Estudio intertextual sobre la persuasión de la palabra en Encomio de Helena y La Celestina», Eviterna 3 (2018), s.p. [en línea, <https://www.revistaeviterna.com/basanez>, fecha de consulta: 13 de septiembre de 2019].

El presente artículo pretende vincular dos obras canónicas de las literaturas griega y española en un ejercicio de intertextualidad que se centra en la experiencia de la persuasión de la palabra que se ejerce sobre diversos actantes pertenecientes a sendos textos. En última instancia se pretende, así, poner en relieve que el análisis comparatístico permite aproximar la génesis de la literatura universal a pesar de los diferentes contextos nacionales y sociopolíticos que separan las producciones artísticas, lo que desdibuja la idea de literaturas nacionales y aspira a abrir nuevas posibilidades de exploración del arte en forma de palabra escrita [resumen del autor].

2613. BASTIANES, María, "La segunda Celestina de la CNTC a la luz de la historia escénica de la obra de Rojas». En El teatro en tiempos de Isabel y Juana, 1474-1517, ed. Felipe Pedraza Jiménez. Cuenca: Universidad de Castilla la Mancha, 2017, 27-40.

Un estudio del segundo montaje de $L C$ por la Compañía Nacional de Teatro Clásico que se llevó a las tablas en la temporada 2015-2016. La autora se enfoca en el cambio de representación e interpretación que interesó a la obra: de una primera lectura escénica "alegre o gozosa» (que la misma compañía mostró en su primer montaje en 1988) a una versión más oscura y lúgubre (la que aquí se reseña y analiza).

2614. BASTIANES, María, «Un clásico difícil. Censura y adaptación escénica de La Celestina bajo el franquismo", Hispanic Research Journal 19.2 (2018): 117-134 [en línea, <https://doi.org/10.1080/14682737.2018.14 44417>, fecha de consulta 13 de septiembre de 2019].

El artículo se propone estudiar los problemas que atravesó la elaboración de versiones escénicas de $L C$ durante el franquismo: de qué manera artistas y censores operaron con un clásico que desafiaba los límites impuestos en lo tocante a moral, religión y política. Para ello, se han analizado diversas versiones de este período, teniendo en cuenta la documentación que se halla en los respectivos expedientes de censura teatral. Este trabajo ha permitido observar cómo a lo largo de la época franquista se fueron configurando, en relación con las solicitudes de autorización, una serie de argumentos para aprobarlas o no por parte de los censores, y de técnicas y tácticas para evadir la censura 
por parte de adaptadores y directores [adaptación del resumen de la autora].

2615. BAZÁN BONFIL, Ricardo, «El prólogo y la recepción condicionada. Una propuesta de lectura», Destiempos 26 (2010): 49-63 [en línea, <http://www.destiempos.com/n26/bazan1.htm>, fecha de consulta: 13 de septiembre de 2019].

Unas reflexiones que se enfocan en los materiales paratextuales -en particular en la carta "El autor a un su amigo" y el prólogo- cuya influencia sobre la lectura e interpretación de la obra misma sería mucho más importante de lo que se ha pensado hasta ahora.

2616. BAZÁN BONFIL, Ricardo, "Sobre las lecturas éticas de La Celestina», Destiempos 26 (2010): 77-93 [en línea, <http://www.destiempos. com/n26/bazan2.htm>, fecha de consulta: 13 de septiembre de 2019]..

Unas consideraciones sobre el "extra» que cada lector siente al terminar de leer $L C$ y sobre la intención del autor al escribir la obra.

2617. BELTRÁN, Rafael, "Sospechosas dolencias de viejas quejosas: Paltrana (Segunda Celestina), Alisa (La Celestina) y otras madres de comedia olvidadas de su obligación", Celestinesca 42, (2018): 443-476 [en línea, $<$ http://parnaseo.uv.es/Celestinesca/Celestinesca42/21_Beltran_Rafael.pdf>, fecha de consulta: 13 de septiembre de 2019].

El artículo estudia el personaje de Paltrana, la madre de Polandria, en la Segunda Celestina de Feliciano de Silva, en relación con otras madres de comedia que desempeñan un papel parecido. Se trata de madres descuidadas o ajenas a la gravedad de los hechos en los que participan sus hijas. Se compara a Paltrana con Alisa, en LC de Fernando de Rojas, con Teodora, en La Dorotea de Lope de Vega, y con otras «buenas» madres de comedia o poesía. Se comparan sus comportamientos y sus dolencias con los síntomas de la enfermedad del amor, en sus distintas variantes [adaptación del resumen del autor].

2618. BERNABÉ, Estefanía, "Del Buen amor a La Celestina: apuntes sobre dos siglos de mujeres bajomedievales», Roda da Fortuna 2.1 (2013): 273296 [en línea, <https://www.revistarodadafortuna.com/2013-1>, fecha de consulta: 13 de septiembre de 2019].

La autora analiza cómo se representa el rol femenino en el Libro de buen amor y LC para proponer algunas conclusiones sobre la mujer en la Edad Media, por un lado, y sobre los oficios o profesiones que esta desarrollaba, por otro. Sin embargo, al etiquetar las actividades profesionales femeninas medievales se solapan a menudo varias ocupaciones, muy especialmente en el caso de la tercera o medianera (Trotaconventos y Celestina) [adaptación del resumen de la autora]. 
2619. BERNALDO DE QUIRÓS MATEO, José Antonio, La "Celestina» primitiva: restauración del texto original, anterior a los desaciertos de Fernando de Rojas. Madrid: Liceus, 2017.

El autor culmina su hipótesis de que en $L C$ hay dos partes bien diferenciadas: la obra primitiva del autor anónimo (actos I a XIV) y las aportaciones de Rojas (el resto e interpolaciones en los primeros catorce actos). Reconstruye aquí el texto que habría sido el del autor anónimo, únicamente retirando lo que él asigna a Rojas.

2620. BLINI, Lorenzo, "La Celestina in versi di Juan de Sedeño (1540)», en "Pueden alzarse las gentiles palabras" per Emma Scoles, eds. Ines Ravasini e Isabella Tomassetti. Roma: Bagatto Libri, 2013, 63-82.

Repaso a los resultados de la investigación doctoral del autor sobre la $T C M$ en verso de Juan de Sedeño, con una perspectiva de 25 años que aporta cierta actualización, sobre todo bibliográfica, al tema. Comienza con lo sabido sobre el autor, continúa con la fidelidad al texto en prosa $y$ las adaptaciones necesarias para transformarlo en verso, y finaliza con una reflexión sobre la edición de la TCM que pudo servir de modelo.

2621. BOTTA, Patrizia, «La contaminación en N, la traducción italiana de La Celestina», Creneida 4 (2016): 107-121 [en línea, <http://www.cre neida.com/revista/creneida-4-2016/la-contaminaci\%C3\%B3n-en-nla-traducci\%C3\%B3n-italiana-de-la-celestina-patrizia-botta>, fecha de consulta: 13 de septiembre de 2019].

En estas páginas se estudia un ejemplo de contaminación en la tradición textual de La Celestina, el de N, la primera traducción italiana de la obra (Roma 1506) que, aun derivando de una rama baja de la Tragicomedia en 21 actos, exhibe sin embargo constantes contaminaciones con la primitiva redacción del texto (ya sea de la fase manuscrita, ya de la fase impresa de la Comedia en 16 actos, o bien de la fase primeriza de la Tragicomedia en 21 actos). El contaminador de los textos es su antecedente español, $\gamma^{3}$, perdido, y de dicha contaminación, salvo N, no queda traza en ninguno de los testimonios coetáneos [resumen de la autora].

2622. BRAEKKAN, Kristian, "The Carnival in Rojas' Celestina: Destroying Hierarchies and the Subversive Side of Laughter», International Journal of Humanities and Social Science Review 3.2 (2017): 1-9 [en línea, $<$ http://www.ijhssrnet.com/uploades/volumes/1575569835.pdf>, fecha de consulta: 13 de septiembre de 2019].

Una lectura crítica de la obra desde una perspectiva baijtiniana con el objetivo de señalar cómo esta cuestiona la cultura patriarcal dominante. Las risas y la comicidad a lo largo de $L C$ indican cómo todo el texto está permeado de una cultura carnavalesca que subvierte y destruye 
el orden y las jerarquías del mundo medieval. Según esta visión e interpretación, también la muerte de Melibea adquiere un nuevo valor y significado: no más algo trágico sino más bien un gesto más de la cultura del carnaval que desafía la autoridad representada por el padre (y su muerte representaría una liberación).

2623. CÁCERES AGUILAR, Dagoberto, «Realismo incesante: desde Celestina hacia su recepción», Edad de Oro 34 (2015): 201-215 [en línea, $<$ https://revistas.uam.es/edadoro/article/view/2670>, fecha de consulta: 13 de septiembre de 2019].

Desde el siglo XVI hasta finales del siglo XvII la élite político-religiosa fundamentada en la cosmovisión judeocristiana rechazó con vehemencia LC. Mediatizados por nuevos marcos de referencia, la recepción crítica de los siglos XX y XXI ha interpretado la obra como una transgresión de los discursos oficiales y la ha usado para celebrar, rechazar o subvertir ideas del espacio social y la subjetividad dentro del complejo cultural hispánico. El propósito del presente artículo es determinar cómo $L C$ afecta a las concepciones de realidad de sus lectores. A través del análisis de la interacción texto-receptor este estudio ofrece un mejor entendimiento de la lectura realista [adaptación del resumen del autor].

2624. CANET, José Luis, "De nuevo sobre la autoría de La Celestina», Letras 77 (2018): 35-68 [en línea, <http://erevistas.uca.edu.ar/index.php/LET/ article/view/1710>, fecha de consulta: 13 de septiembre de 2019].

El tema de la autoría y si fueron uno (Fernando de Rojas) o más escritores los creadores de $L C$ es una polémica larga en la historia literaria. En este trabajo se pone en entredicho que el bachiller Fernando de Rojas de la Puebla de Montalbán, perteneciente a una familia de conversos que llegó a ser alcalde de Talavera, sea realmente su artífice. Para ello se repasan las diferentes opiniones sobre la autoría de la obra a lo largo de los siglos hasta el momento, en donde las dudas superan con creces las certezas, cuando multitud de críticos (entre ellos se incluye el autor del presente artículo) ya no creen que Rojas y un primer Autor (Mena y/o Cota) sean los verdaderos progenitores de la CCM y su ampliación a TCM, tal como se afirma en los versos acrósticos [adaptación del resumen del autor].

2625. CAPPELLI, Guido, "Colpo d'occhio sulla Celestina. La satira dell'umanesimo: una proposta di interpretazione», en "La Celestina»: ecdotica e interpretazione, ed. Francisco Lobera Serrano. Roma: Bagatti Libri, 2010, 159-178.

Estudia la relación de $L C$ con la literatura castellana contemporánea en la búsqueda de un sistema literario y/o ideológico-temático que 
unifique y explique la abundancia de citas y otras formas de intertextualidad, así como su finalidad. Atribuye a un deseo de parodiar la moral humanista el tratamiento subversivo del tema de la amistad, de la mansa pobreza y, en general, de los temas queridos al humanismo que aparecen en la obra, volviendo continuamente a la categorización de Rojas como converso para apoyar su rechazo a los mismos. Concluye que la acción de $L C$ contradice sistemáticamente las aspiraciones éticas y cívicas del humanismo para retratar una realidad que es todo lo contrario de los valores humanistas, poniendo de manifiesto su fundamental hipocresía e inutilidad.

2626. CAPPELLO, Sergio, "La Célestine (1527). Roman en dialogues», en Il romanzo a teatro. Atti del Convegno internazionale della Società Universitaria per gli Studi di Lingua e Letteratura Francese (SUSLLF), Verona, 11-13 novembre 2004, ed. Franco Piva. Fasano: Schena, 2005, 199-209.

Ubica la traducción anónima francesa de LC (1527) en el género de la novela con argumentos editoriales (el impresor se especializa en relatos de ficción en prosa, sin apenas evidencias de obras dramáticas), comerciales (se dirige al mismo tipo de lector que los relatos sentimentales en prosa), de afinidad temática (las similitudes con los relatos sentimentales italianos) y relacionados con la recepción (los moralistas ubican $L C$ al mismo nivel que las obras de ficción en prosa) y con la transmisión (lectura dramatizada en lugar de representación escénica). Se trataría, no obstante, de una novela en diálogos. Esto contribuye, por un lado, a ocultar la voz del narrador/autor, por otro, permite profundizar más en los temas del universo ficcional por medio de la contraposición de las diferentes posturas asumidas por los personajes en el diálogo y sus estrategias dialécticas. Estas son las que permiten la crítica a las argumentaciones sofísticas, que no podrían haber sido adecuadamente reflejadas en prosa tradicional.

2627. CÁSEDA TERESA, Jesús Fernando, «El autor del primer acto de la Comedia de Calixto y Melibea: el arcipreste de Talavera, Alfonso Martínez de Toledo", Celestinesca 42 (2018): 9-56 [en línea, $<$ http://parnaseo.uv.es/Celestinesca/Celestinesca42/01_Caseda_Jesus.pdf >, fecha de consulta: 13 de septiembre de 2019].

El autor intenta demostrar que Alfonso Martínez de Toledo fue el autor del primer acto de la CCM y, probablemente, también de la estructura general de la primera versión de la obra. El análisis se centra, entre otras cosas, en la figura de Calisto en relación con la biografía de Alfonso Martínez de Toledo, la presencia de referencias al reino de Aragón, la ubicación de la acción en Barcelona, la comunidad de forma y estilo entre el Corbacho y $L C$, etc. 
2628. CHICOTE, Gloria, "Una lectura discursiva de La Dorotea desde la tradición celestinesca», Olivar: Revista de Literatura y Cultura Españolas 18.28 (2018): s.p. [en línea, <https://www.olivar.fahce.unlp.edu.ar/article/view/OLIe036>, fecha de consulta: 13 de septiembre de 2019].

Este artículo propone una comparación entre La Celestina y La Dorotea en función de sus particularidades discursivas. A partir del reinado de los Reyes Católicos se produjeron una serie de innovaciones literarias que modelaron una línea creativa con proyección hasta el Siglo de Oro: la configuración de un autor autoconsciente que se narra a sí mismo, la desaparición de reglas tradicionales de estilo para la construcción de personajes-tipo, el empleo innovador de un "estilo copioso" en el que proliferan y se entrelazan vocablos de diferentes etimologías $y$ registros [resumen de la autora].

2629. COSTA FONTES, Manuel da, El arte de la subversión en la España inquisitorial. Fernando de Rojas y Francisco Delicado (con dos notas sobre Cervantes). Madrid \& Frankfurt am Main: Iberoamericana \& Vervuert, 2018.

Traducción actualizada de The Art of Subversion in Inquisitorial Spain: Rojas and Delicado, consignado en la segunda etapa de este suplemento bibliográfico con el número 1731.

2630. DEYERMOND, Alan, «El libro de texto mal empleado: Andreas Capellanus y la escena inicial de La Celestina», Medievalia 50 (2018): 43-47 [en línea, <https://revistas-filologicas.unam.mx/medievalia/index.php/ mv/article/view/234>, fecha de consulta: 13 de septiembre de 2019].

Traducción del artículo "The Text-book Mishandled: Andreas Capellanus and the Opening Scene of La Celestina», consignado en la primera etapa de este suplemento bibliográfico con el número 2588.

2631. DIAGO MONCHOLÍ, Manuel Vicente, "José Ricardo Morales y La Celestina", Artescena 6 (2018): 1-9.

El artículo aborda la recepción crítica del montaje que José Ricardo Morales realizó de La Celestina en 1949 con el Teatro Experimental de la Universidad de Chile a partir de una adaptación propia. En octubre de 1949 Margarita Xirgu estrenaba con la Comedia Nacional de Uruguay, en el Teatro Solís de Montevideo, la versión de LC que le había encomendado a José Ricardo Morales, joven dramaturgo español por entonces exiliado en Chile. Apenas un mes después, en noviembre de ese mismo año, Morales daba a conocer su propia puesta en escena de la obra en el Teatro Municipal de Santiago, al frente del Teatro Experimental de la Universidad de Chile, del que había sido uno de sus fundadores [resumen del autor]. 
2632. DI PATRE, Patrizia, «A la sombra del De amore. Dante entre Capellanus y La Celestina», Celestinesca 42 (2018): 57-82 [en línea, <http:// parnaseo.uv.es/Celestinesca/Celestinesca42/02_Di_Patre_Patrizia. pdf $>$, fecha de consulta: 13 de septiembre de 2019].

Se muestra cómo la obra de Andreas Capellanus está organizada según el patrón clásico de una quaestio medieval y responde a los mismos objetivos de declaración formal y exhaustiva —en pro y contrade una tesis finalmente llevada a su solución definitiva. La conclusión autorial en De amore es contraria a la apología del amor profano, cuyos efectos nefastos recorren toda la veta literaria que culmina con los desafortunados amores la TCM [adaptación del resumen de la autora]

2633. FERNÁNDEZ-JÁUREGUI ROJAS, Carlota, «The Footprint Fallacy: Celestina's Resistance to Intention", Hispanic Review 85.4 (2017): 371392 [en línea, <https://muse.jhu.edu/article/676107>, fecha de consulta: 13 de septiembre de 2019].

Este estudio revisa el debate en torno a la intencionalidad de Celestina. Para ello, pone en relación la intención con la ironía y la paralipsis, y estudia la relación entre intención, significado e interpretación. La ruptura entre la palabra y la intención se analiza desde las perspectivas del simbolismo financiero y de la manera en la que el autor se desvincula de las consecuencias de sus intenciones. Como resultado, en $L C$ se descubre una resistencia intrínseca a la intencionalidad, que cristaliza en lo que la autora denomina «footprint fallacy» [adaptación del resumen de la autora].

2634. FERNÁNDEZ-RIVERA, Enrique, y Antonio CORTIJO OCAÑA, eds., "Cincuenta de quinientos años de La Celestina», eHumanista 19 (2011): viii-xviii [en línea, <https://www.ehumanista.ucsb.edu/sites/secure.lsit. ucsb.edu.span.d7_eh/files/sitefiles/ehumanista/volume19/2\%20ehuma nista.celestina.intro.fdez-cortijo.pdf $>$, fecha de consulta: 13 de septiembre de 2019].

Introducción al volumen-homenaje a la profesora María Rosa Lida de Malkiel.

2635. FERNÁNDEZ-RIVERA, Enrique, "Celestina, a Tragic Music Comedy de Brad Bond: Creación y evolución de un musical de Broadway", Celestinesca 42 (2018): 83-142 [en línea, <https://parnaseo.uv.es/Celes tinesca/Celestinesca42/03_Fernandez_Enrique.pdf $>$, fecha de consulta: 13 de septiembre de 2019].

Se da a conocer el libreto de la adaptación de $L C$ que compuso Brad Bond y que, con el título de Celestina, a Tragic Music Comedy, se estrenó en Broadway en 1999. Se presenta también una breve historia tex- 
tual de esa versión desde su creación hasta su llegada al escenario y se analizan los puntos en que sigue al original (argumento general de la obra y personajes) y los en que se aleja de él (la historia se desarrolla en el mundo moderno, en una ciudad costera de EE.UU., etc.).

2636. FERNÁNDEZ-RIVERA, Enrique, «La picaresca y la celestinesca en las pantallas españolas de los sesenta a los ochenta", eHumanista 38 (2018): 873-889 [en línea, <https://www.ehumanista.ucsb.edu/ sites/secure.lsit.ucsb.edu.span.d7_eh/files/sitefiles/ehumanista/volu me38/12\%20ehum38.efernandez.pdf $>$, fecha de consulta: 13 de septiembre de 2019].

Las adaptaciones cinematográficas de la picaresca y la celestinesca de mediados de los sesenta a mediados de los ochenta reflejan mucho de la época a la que pertenecen. El franquismo había producido versiones edulcoradas de estos títulos para la televisión, insistiendo en su naturaleza canónica y reduciendo al máximo las referencias al sexo, la irreligiosidad y la crítica social. Con la Transición se fueron incorporando cada vez más de estos elementos, con especial énfasis en el sexo, en consonancia muchas veces con el fenómeno del Destape. A partir de mediados de los ochenta desapareció el interés por estos textos, desplazados por otros temas más atractivos para los nuevos tiempos y el nuevo público [adaptación del resumen del autor].

2637. FRANÇOIS, Jéromine, «Reescribir La Celestina del siglo XIX al XXI: estrategias peritextuales», Bibliographica 1.2, (2018): 169-220 [en línea, $<$ https://doi.org/10.22201/iib.bibliographica.2018.2.17>, fecha de consulta: 13 de septiembre de 2019].

Este trabajo esclarece la recepción de $L C$ en treinta reescrituras españolas e hispanoamericanas de la TCM publicadas desde el siglo XIX hasta principios del XXI. En él se analizan las diferentes estrategias peritextuales para, en lugar de modernizar o imitar su modelo, reinventar su trama y personajes. Las elecciones formales y temáticas de las portadas, los (sub)títulos, prólogos, epígrafes y epílogos realzan el mismo procedimiento de la reescritura, sus métodos y objetivos. Por eso el análisis del peritexto permite entender mejor el funcionamiento y las implicaciones hermenéuticas de esta peculiar producción celestinesca [adaptación del resumen de la autora].

2638. FRANÇOIS, Jéromine, «Areúsa: de Fernando de Rojas a Angelina Muñiz-Huberman", Lejana. Revista Crítica de Narrativa Breve 9 (2016): s.p. [en línea, <http://ojs.elte.hu/index.php/lejana/article/view/112>, fecha de consulta: 13 de septiembre de 2019].

Este estudio examina la relevancia y las funciones de los juegos intertextuales entre $L C$ y la novela mexicana Areúsa en los conciertos (2002) 
de Angelina Muñiz-Huberman. Por una parte, las referencias celestinescas inician una crisis global de la protagonista epónima, que llega a cuestionar su identidad y su marco espaciotemporal. Por otra parte, con el fin de sobrepasar su estado de crisis, la Areúsa mexicana recupera ingredientes de la Areúsa medieval —su erotismo desenfrenado, su inconformidad social - para elaborar una reflexión contemporánea sobre la sexualidad femenina y las normas sociales que la restringen [adaptación del resumen de la autora].

2639. FRANÇOIS, Jéromine, «El espacio de la alcahueta: el marco urbano en La Celestina y La Lozana andaluza», Medievalia 48 (2016): 107-129 [en línea, <https://revistas_filologicas.unam.mx/medievalia/index.php/ mv/article/view/322>, fecha de consulta: 13 de septiembre de 2019].

Este artículo propone una comparación del tratamiento del espacio en La Celestina de Fernando de Rojas y en La Lozana andaluza de Francisco Delicado. A través de un estudio del marco urbano, de los recorridos, de la organización espacial en casas-calles-umbrales, y de la dicotomía entre lo público y lo privado, se evidencian el diálogo y la relación de rivalidad que Delicado inicia con su predecesor a partir de la topografía de su texto. Se verá que, aunque en ambos textos el personaje de la alcahueta se apodera de una configuración espacial urbana para cumplir con su faena, Celestina nivela los espacios destruyendo sus fronteras mientras que Lozana más bien tiende a crear nuevos espacios y a volverse una verdadera gestora del marco espacial. En este estudio se argumentará asimismo sobre las formas y funciones que $\mathrm{La}$ Lozana atribuye al espacio con el fin de posicionarse con respecto a su exitosa antepasada [resumen de la autora].

2640. FRANÇOIS, Jéromine, "La Celestina como hipotexto generador de rupturas narrativas en la literatura hispánica actual: el caso de Manifiesto de Celestina (1995) de Marta Mosquera", Revista Crítica de Narrativa Breve 8 (2015): [en línea, <http://ojs.elte.hu/index.php/lejana/ article/view/93>, fecha de consulta: 13 de septiembre de 2019].

El Manifiesto de Celestina (1995) de la escritora argentina Marta Mosquera representa una verdadera mise en abyme del texto clásico de Rojas. En esta novela fantástica, la intertextualidad con La Celestina genera además una serie de rupturas en la construcción de la novela. En este trabajo, veremos así que el cronotopo, la trama y el narrador se disgregan a medida que se multiplican las citas de la Tragicomedia. Se argumentará luego sobre la reflexión acerca de la literatura y su reescritura a la que da lugar tal proceso de rupturas [resumen de la autora].

2641. FRANÇOIS, Jéromine, "La Celestina interroga el código teatral: Tragedia fantástica de la gitana Celestina de Alfonso Sastre», Revista de Lite- 
ratura 78.156 (2016): 525-541 [en línea, <https://doi.org/10.3989/revli teratura.2016.02.022>, fecha de consulta: 13 de septiembre de 2019].

El dramaturgo español Alfonso Sastre quería transformar el teatro de su época en una plataforma de crítica social. En este marco, elaboró en sus obras dramáticas una serie de estrategias de distanciamiento que desvelaban al espectador los engranajes de la representación para incitarlo a buscar el sentido de la construcción disecada ante sus ojos. En la Tragedia fantástica de la gitana Celestina, dichas estrategias se desarrollan a partir del texto clásico de Rojas. En este estudio, se analiza así en qué medida Sastre utiliza personajes y citas de La Celestina para generar técnicas metateatrales que atañen tanto a la identidad de los personajes como a las acotaciones o a los diálogos, y que provocan un proceso de mise en abyme de la obra teatral [resumen de la autora].

2642. FRANÇOIS, Jéromine, "La constitution d'un mythe littéraire: $L a$ Célestine à l'époque contemporaine», Littératures 74 (2016): 149-158 [en línea, <https://journals.openedition.org/litteratures/550>, fecha de consulta: 13 de septiembre de 2019].

Algunas reelaboraciones contemporáneas de $L C$ han contribuido a elevarla a la posición de mito literario. Estas reapropiaciones modernas revelan no solo un profundo conocimiento de la obra, sino también una voluntad de mostrar su plasticidad sometiéndola a los moldes de la literatura actual. En este trabajo se explora el concepto de «reescritura» a través de $L C$, partiendo de la idea de mythodologie (metodología + mitología) y analizando el proceso por el cual un personaje literario es capaz de convertirse en parte del patrimonio colectivo [adaptación del resumen de la autora].

2643. FRANÇOIS, Jéromine, "Celestina en Hispanoamérica: la nostalgia de los buenos viejos tiempos como tópico celestinesco en Toro-Garland, Fuentes y Mosquera", Celestinesca 42 (2018): 143-156 [en línea, $<$ https://parnaseo.uv.es/Celestinesca/Celestinesca42/04_Francois_Jeromine.pdf $>$, fecha de consulta: 13 de septiembre de 2019].

Un estudio intertextual del tópico celestinesco de la nostalgia de los «buenos viejos tiempos» y de cómo ha sido recibido, adaptado y recreado en tres obras hispanoamericanas, las tres reescrituras literarias de la obra maestra española, de la segunda mitad del siglo xx: Razón y pasión de enamorados (1973) de Fernando Toro-Garland, Terra Nostra (1975) de Carlos Fuentes y Manifiesto de Celestina (1995) de Marta Mosquera.

2644. FRANÇOIS, Jéromine, Joseph Thomas Snow, María Bastianes y Emily C. Francomano. «La Celestina de José Luis Gómez: cuatro apreciaciones», Celestinesca 40 (2016): 205-220 [en línea, <https://parnaseo. 
uv.es/Celestinesca/Celestinesca40/Resena_Gomez_Snow.pdf >, fecha de consulta: 13 de septiembre de 2019].

Cuatro reseñas de cuatro celestinistas de la adaptación escénica de José Luis Gómez.

2645. FUNES, Leonardo, "Hacia Celestina: paradojas del ideal amoroso cortesano en los textos sentimentales castellanos», Letras 77 (2018): 85-96 [en línea, <http://erevistas.uca.edu.ar/index.php/LET/article/ view/1713>, fecha de consulta: 13 de septiembre de 2019].

El trabajo es una indagación de ciertos aspectos de la ideología amorosa cortesana en la Castilla del siglo xV (de los tiempos de Juan II hasta los de Isabel I), específicamente la compleja construcción de la relación jerárquica entre el enamorado y su Dama en los textos de ficción sentimental. Se plantea como hipótesis que esa construcción es esencialmente paradójica y que esas paradojas conforman una suerte de subtexto sobre el cual se teje la trama de la Tragicomedia de Calisto y Melibea. A partir de la idea de Fernando Gómez Redondo de que la Tragicomedia pertenece al género de la ficción sentimental, y aprovechando ciertos planteos de Roger Chartier en su lectura de la obra de Norbert Elias, se buscará entender en qué horizonte deben interpretarse las resonancias de sentido del texto celestinesco [resumen del autor].

2646. GARCÍA ÁLVAREZ, Juan Pablo Mauricio, "Configuración y difusión de la Segunda Celestina de Feliciano de Silva. Presentación", Celestinesca 42 (2018): 319-321 [en línea, <http://parnaseo.uv.es/Celestinesca/Celestinesca42/15_Seccion_Segunda_Celestina.pdf $>$, fecha de consulta: 13 de septiembre de 2019].

Presentación del dossier sobre la Segunda Celestina en el número 42 de Celestinesca.

2647. GARCÍA-BERMEJO, Miguel, "Los sigilosos secretos en la sanación: de Celestina a don Quijote con su bálsamo de Fierabrás», en De la magia al escepticismo: literatura, ciencia y pensamiento en los siglos XVI-XVIII, ed. Mariona Sánchez Ruiz. Girona: Documenta Universitaria, 2018, 37-58.

Ubica la receta del bálsamo de Fierabrás y los saberes médicos de Celestina en el contexto de los libros y los profesores de secretos, y de los sanadores y los empíricos, personajes históricos de los siglos XV y XVI.

2648. GARCÍA-BERMEJO, Miguel, "Poder, experiencia y secretos en la Segunda Celestina de Feliciano de Silva", Celestinesca 42 (2018): 477498 [en línea, <http://parnaseo.uv.es/Celestinesca/Celestinesca42/22_ Garcia_Miguel.pdf>, fecha de consulta: 13 de septiembre de 2019]. 
Este trabajo estudia la transformación que experimentan la presencia y empleo de la magia y el conocimiento como fundamento del poder de la alcahueta en los textos de la Comedia Thebayda y la Segunda Celestina de Feliciano de Silva respecto de la TCM original. Para poder apreciar el cambio se establecen sus funciones en la acción del texto de Rojas, a partir del análisis de varios lugares de la acción que rodean a su aparición, y se revisa con minuciosidad el sentido que adquieren en los primeros textos extensos que se han conceptuado como la rama cómica de las imitaciones celestinescas [adaptación del resumen del autor].

2649. GARCI-GÓMEZ, Miguel, "El ximio de la abuela y el cuchillo del abuelo de Calisto: porradas de Sempronio", artículo digital, s.a., s.p. [en línea, <http://people.duke.edu/ garci/cibertextos/GARCI-GOMEZ/EL-XIMIO.HTM>, fecha de consulta: 13 de septiembre de 2109].

Refundición del artículo de 2006 «El ximio [mono] de la abuela y el cuchillo del abuelo de Calisto: identificación", consignado en este suplemento bibliográfico con el número 1810 (segunda etapa).

2650. GARGANO, Antonio, “'Quando i’ fui preso'. Primeros encuentros amorosos, de Dante a Fernando de Rojas", Rivista di Filologia e Letterature Ispaniche 21 (2018): 167-190 [en línea, <https://riviste.edizioniets. com/rfli/index.php/rfli/article/view/193>, fecha de consulta: 13 de septiembre de 2109].

Se analiza el tema del encuentro amoroso en tres obras maestras de la literatura europea; dos de ellas, la Vita nuova y la Elegia di Madonna Fiammetta (sin olvidar su relación con el Filocolo), se enfocan como paralelos formales y antecedentes temáticos del episodio del encuentro entre Calisto y Melibea en La Celestina de Fernando de Rojas [resumen del autor].

2651. GARGANO, Antonio, "Sacarle he lo suyo y lo ajeno del buche'. Segretezza d'amore desiderio di vendetta nella Celestina», en "Pueden alzarse las gentiles palabras» per Emma Scoles, eds. Ines Ravasini e Isabella Tomassetti. Roma: Bagatto Libri, 2013, 213-226.

Relaciona la transgresión del secreto en $L C$ con la transgresión de las convenciones del amor cortés por parte de Calisto y la de las convenciones morales sociales por parte de Melibea, pero también con su alto estado social. Paralelamente, el secreto se asocia con actividades no aceptables socialmente, que por su carácter reprobable precisamente tienen que realizarse lejos de las miradas de la sociedad, en las cuales prima la satisfacción del deseo, un sentimiento también problemático a ojos de la colectividad y una motivación mucho menos noble que las del amor y la reputación que caracterizan la primera clase de deseo. El secreto también resulta fundamental para el Auto de Centurio, ya que 
es gracias a la traición del mismo que la venganza de las prostitutas es posible. En todos estos casos, el secreto se degrada, hasta acabar comparado a las funciones corporales básicas.

2652. GERMETEN, Nicole von, «From Whores to Prostitutes». En Profit and Passion: Transactional Sex in Colonial Mexico. Oakland: University of California Press, 2018, 36-49 [en línea, <https://california.universitypressscholarship.com/view/10.1525/california/9780520297296.001.0001/upso-9780520297296-chapter-003>, fecha de consulta: 15 de septiembre de 2019].

Comenzando con $L C$, este capítulo de libro estudia la evolución de la terminología para designar a las mujeres públicas y, a través de la misma, los cambios en su status [adaptación del resumen de la autora].

2653. GERNERT, Folke, "'Cuanto va de la excellencia del alma a la del cuerpo': la legibilidad del cuerpo humano en la Segunda Celestina de Feliciano de Silva", Celestinesca 42 (2018): $421-442$ [en línea, <http:// parnaseo.uv.es/Celestinesca/Celestinesca42/20_Gernert_Folke.pdf>, fecha de consulta: 13 de septiembre de 2019].

El presente artículo estudia los signos corporales y su significado en la Tragicomedia de Rojas, la Segunda Celestina de Feliciano de Silva y otras obras celestinescas. Esta legibilidad del cuerpo humano se explica por la amplia difusión de las teorías fisiognómicas a lo largo de los siglos XV y XVI. Por lo tanto, no sorprende que los propios personajes muestran una clara conciencia de la relación entre el aspecto exterior y la personalidad. En las obras analizadas, el hirsutismo femenino o las cicatrices pueden ser interpretados como alusiones al carácter de un personaje o de su estatus social marginado. Asimismo, las descripciones de la fealdad y de la hermosura de los personajes femeninos no responden sólo a los cánones poetológicos de la época, sino son susceptibles de ser leídos en clave fisiognómica [resumen de la autora].

2654. GÓMEZ GOYZUETA, Ximena, «El encuentro imposible entre Celestina y Alisa: una lectura mediante el adynaton», eHumanista 37, (2017): 669-679 [en línea, <https://www.ehumanista.ucsb.edu/sites/secure.lsit.ucsb.edu.span.d7_eh/files/sitefiles/ehumanista/volume37/36\%20ehum37.gomez.pdf $>$, fecha de consulta: 13 de septiembre de 2019].

Se analiza el adynaton como recurso retórico-poético que permite ver a Celestina como un personaje capaz de convocar a lo imposible: Alisa representaría una de las puertas de entrada para que la alcahueta cumpla con su cometido tras la inversión del mundo que ella misma provoca, y que caracteriza una de las formas en las que se representa el mundo en la obra [adaptación del resumen de la autora]. 
2655. GONZALO SÁNCHEZ MOLERO, José Luis, "Las obras de Feliciano de Silva en los inventarios de las bibliotecas hispánicas del Siglo de Oro: lectura y presencia», Celestinesca 42 (2018): 339-374 [en línea, $<$ https://parnaseo.uv.es/Celestinesca/Celestinesca42/17_Gonzalo_ Jose_Luis.pdf>, fecha de consulta: 13 de septiembre de 2019].

En este artículo se aborda la presencia de la obra literaria de Feliciano de Silva en los inventarios y catálogos españoles e indianos durante el siglo XVI. Para ello se analiza la tipología social de los lectores de las obras de Silva, la distribución comercial de sus ejemplares y sus formas de lectura. También se indaga, a la luz de los lectores, sobre las vinculaciones del propio autor con las cortes española y portuguesa y se analiza cómo la presencia y posteriores ausencias de sus obras en los inventarios, permiten comprobar el papel de los libros de caballerías como lectura de consumo y entretenimiento, sufriendo los avatares de las modas lectoras [adaptación del resumen del autor].

2656. GORGA LÓPEZ, Gemma, "Spatial Metaphors of Desire in the Divina Commedia and in La Celestina», Rivista di Filologia e Letterature Ispaniche 21 (2019): 191-200 [en línea, <https://riviste.edizioniets.com/rfli/index.

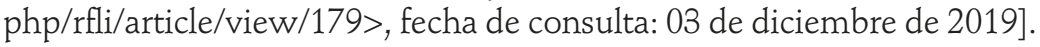

Mediante el análisis de cuatro elementos espaciales (el centro, el límite, la verticalidad y la línea recta), este trabajo explora la naturaleza simbólica del espacio en $L C$ de Fernando de Rojas y La divina commedia de Dante. En ambos trabajos el espacio va más allá de la simple geografía y se llena de significados morales [adaptación del resumen de la autora].

2657. GUARDIOLA MORILLAS, Juan, "Una lucha contra la bilis negra: La Lozana andaluza y los analgésicos del amor y la parodia», Celestinesca 42 (2018): 157-188 [en línea, <http://parnaseo.uv.es/Celestinesca/Celestinesca42/05_Guardiola_Juan.pdf>, fecha de consulta: 13 de septiembre de 2019].

En el estudio se señala cómo tanto Francisco Delicado como la misma Lozana lograrían mitigar, a través de las continuas referencias al amor y al erotismo y a su representación, su dolencia melancólica y el malestar causado por la sífilis. Se indican también algunos antecedentes y modelos (tratados amorosos y médicos y la ficción sentimental) con el objetivo de mostrar cómo el autor logra subvertir su mensaje con fines paródicos.

2658. GUGLIELMI, Nilda, "Celestinas en el tiempo», en Los judíos entre la Antigüedad tardía y la Edad Media, monográfico de Temas Medievales 25.2 (2018), 165-178 [en línea, <http://temasmedievales.imhicihu-conicet.gov.ar/index.php/TemasMedievales/article/view/48>, fecha de consulta: 13 de septiembre de 2019]. 
Este artículo analiza el personaje de la alcahueta: de ordinario presentado como mujer vieja, pobre, con conocimientos de curandera, práctica en afeites, restauradora de "virgos», y también habilidosa en trámites amorosos, en general, prohibidos. Se centra, sobre todo, en la literatura italiana de los siglos XIV y XV, en autores como Francesco de Barberino, san Bernardino y, fundamentalmente, en la obra de Alessandro Piccolomini, La Raffaella (1539). También se analizan enfoques particulares relacionados con Celestina (por ejemplo, la vejez y la envidia) y otras cuestiones relevantes como las confrontaciones entre vieja-joven y madre-hija [adaptación del resumen de la autora].

2659. ÍLKER, Nur Gülümser, "Celestina: Calisto Ve Melibea'nin Trajikomedyasi'nda Ortaçağ Ve Rönesans Arasinda Kalmiş Bïrey Ve Kadin (Individual and Woman between the Middle Ages and the Renaissance in La Celestina: Tragicomedy of Calisto and Melibea)", Selçuk Üniversitesi Edebiyat Fakültesi Dergisi 37 (2017): 343-350 [en línea, <http:// sefad.selcuk.edu.tr/sefad/article/view/725>, fecha de consulta: 13 de septiembre de 2019].

$L C$ aborda el conflicto entre la sociedad medieval y el individuo, que se va acentuando a medida que se acerca el Renacimiento. En esta sociedad, las normas sociales importan más que el individuo, por eso sus personajes protagonistas son castigados por su individualismo y sus pasiones desatadas. En este sentido se trata indudablemente de una obra didáctica. Además de estos aspectos, en esta obra se examina el papel del individuo - y especialmente de la mujer - como sujeto literario entre la Edad Media y el Renacimiento [adaptación del resumen de la autora].

2660. KROLL, Simon, "Amor cortés y amor mercantil: conceptos amatorios enfrentados», Celestinesca 42 (2018): 499-512 [en línea, <http:// parnaseo.uv.es/Celestinesca/Celestinesca42/23_Kroll_Simon.pdf >, fecha de consulta: 13 de septiembre de 2019].

Artículo que sitúa la Segunda Celestina de Feliciano de Silva en su contexto histórico, especialmente en el pensamiento económico de su época. Analiza los diferentes modelos amatorios presentes en el texto, en el que la mayoría de las relaciones amorosas se corresponden con un amor mercantil que reifica al otro. Frente a este amor economizado se dibuja una pareja de amor noble y cortés y un discurso de amor pastoril que pueden verse como contrastes de las relaciones mercantilizadas. Así el texto de Silva, lejos de propagar una vuelta a valores medievales, discute diferentes modelos amatorios e inserta su texto en el contexto de la creciente mercantilización del temprano siglo XVI [adaptación del resumen del autor]. 
2661. LACARRA, María Jesús, "La Tragicomedia de Calisto y Melibea en Zaragoza (1507-1607): los modelos iconográficos y su pervivencia», en La fisonomía del libro medieval y moderno. Entre la funcionalidad, la estética y la información, dir. Manuel José Pedraza Gracia. Zaragoza: Universidad de Zaragoza, 2019, 237-250.

Repaso de las ediciones de LC impresas en Zaragoza. Se relaciona la ausencia de grabados en la edición de 1507 con la tradición de las Comedias de 1500 y 1501. Vincula la edición de 1545 a cargo del sevillano Diego Hernández con la renovación del esquema crombergueriano en 1535, mientras que destaca cómo la edición del mismo año de Jorge Coci crea nuevas estampas de ancho de página ex profeso para su impresión, alejándose de la combinación de figuritas con escenas completas típica anterior y acercándose más al esquema de la CCM de Burgos. La edición de 1554 reutiliza estos mismos grabados, en tanto que la de 1555 vuelve a los grabados de la de Diego Hernández, pero se trata de copias toscas. Finalmente, la edición de 1607 prescinde de ilustrar el texto. La reutilización de modelos y grabados viene explicada con argumentos biográficos sobre los impresores. Por otra parte, se dedican algunas páginas a explicar las innovaciones de la edición impresa por Coci, en la que parece haberse recurrido a los argumentos de cada auto y no a los modelos anteriores para diseñar las ilustraciones, y su historia como inspiración para los grabados de las ediciones de la traducción holandesa y para algunas ediciones ilustradas castellanas. Termina con una reflexión sobre el posible artista autor de los grabados.

2662. LEONETTI, Francesca, "Las enmiendas de los doctos: nuevo estudio crítico y textual de la edición de La Celestina de Salamanca 1570", Critica del Testo 21.2 (2018): 77-97 [en líne, <https://www.viella.it/rivista/9788833131467/4266> fecha de consulta: 13 de septiembre de 2109].

Dentro de los complejos problemas de transmisión textual de $L C$, la edición publicada por Mathias Gast y financiada por Simón Borgoñón en Salamanca en 1570 es conocida como una revisión culta de la obra que restaura algunas de las lecturas originales. Esta edición encaja dentro de la tendencia a mejorar el texto por conjetura y librarlo «de muchos errores que antes tenía", como se puede leer en la portada. El objetivo de este trabajo es demostrar mediante algunos ejemplos que, a pesar de esta afirmación, las enmiendas introducidas en dicha edición se limitan a la revisión de un número muy limitado de loci critici, en los que, efectivamente, se restaura el texto y su lectio difficilior [adaptación del resumen de la autora].

2663. LLOSA, Álvaro, «El canon de belleza femenina en tiempos de $L a$ Celestina a través de textos de la época», Acta Hispanica-Acta Universitatis Szegediensis 4 (1999): 23-37. 
Repasa los ideales poéticos de belleza contemporáneos de $L C$ para intentar determinar si la descripción de Melibea encaja en alguno de ellos. Contrasta el modelo de descripción física de la mujer de tradición medieval (y clásica) con la omisión de los detalles físicos más típica del Renacimiento. Insiste en la necesidad de que las bellezas externa e interna se correspondan, de manera que la mujer ideal lo es también a nivel espiritual y moral, transformándose en la obra maestra de Dios. Y, al contrario, que la fealdad está vinculada a la degradación moral y espiritual. Melibea encaja perfectamente con esta tradición, aunque con pequeñas divergencias que tal vez sean indicios de su carnalidad, luego de su falta de total perfección.

2664. LOBERA, Francisco, ed., "La Celestina»: ecdotica e interpretazione. Roma: Bagatti Libri, 2010.

Volumen editado. Incluimos algunos de los trabajos individuales en el suplemento.

2665. LOBERA, Francisco, «Sobre la escritura del 'hablar' en La Celestina y en el Quijote», Critica del Testo 20.3, (2017): 81-106 [en línea, <https:// www.viella.it/rivista/9788867289820/4072>, fecha de consulta: 13 de septiembre de 2019].

La dificultad de definir qué tipo de lengua castellana usan los personajes de la Comedia o Tragicomedia de Calisto y Melibea nos ayuda a reflexionar sobre la lengua hablada y la lengua hablada en literatura. Por otra parte, el tema del diálogo como género literario del Renacimiento y su relación y diferencia con el diálogo en la narrativa del siglo XVI puede hacernos entender aspectos fundamentales de la singularidad de La Celestina y una posible relación con Don Quijote en la composición y naturaleza del diálogo [resumen del autor].

2666. LÓPEZ GONZÁLEZ, Luis F., «Lucrecia's Role as a Classical Nursemaid in Celestina», Hispania 101.2 (2018): 294-305 [en línea, <https://doi. org/10.1353/hpn.2018.0121>, fecha de consulta: 13 de septiembre de 2019].

La crítica celestinesca no ha prestado suficiente atención al papel de Lucrecia en el desarrollo de la relación entre Calisto y Melibea y en la $T C M$, limitándose a considerarla el arquetipo de la criada desleal. Sin embargo, en este trabajo se defiende que Lucrecia comparte más rasgos con la nodriza clásica, con unos vínculos afectivos mayores que los de la dinámica sirviente-señora. Lucrecia actúa como una madre protectora que, al contrario que Alisa, nunca abandona a Melibea [adaptación del resumen del autor].

2667. MAÑERO LOZANO, David, «Melpómene con Talía. Formas de la tragicomedia en el teatro español anterior a la Comedia nueva», Bulletin 
Hispanique 120.2 (2018): $581-598$ [en línea,<http://doi.org/10.4000/bulletinhispanique.7038>, fecha de consulta: 14 de septiembre de 2019].

Este trabajo ofrece una aproximación a los desarrollos de la tragicomedia en el teatro español del siglo XVI, así como sus relaciones con la tradición europea [resumen del autor].

2668. MARTÍ CALOCA, Ivette, "Todo se ha hecho a mi voluntad": Melibea como eje central de "La Celestina». Madrid: Iberoamericana, 2019.

Alan Deyermond estableció que Melibea comparte las cualidades de la víbora conyugicida que Rojas describe en el Prólogo. La relación entre Melibea y las imágenes serpentinas se agudiza en la tradicional descriptio puellae pulchritudinis que Calisto hace de su amada: inesperadamente la equipara a Medusa. De esta manera, no solo se subrayan y exploran sus cualidades serpentinas, sino que se establece que, más que Celestina, cuyos atributos viperinos son reconocidos por todos, Melibea es quien reclama para sí las vidas de todos los demás personajes. Esto la eleva a legítima protagonista de la TCM y eje de su estructura simbólico formal [adaptación del resumen de la autora].

2669. MARTÍN ROMERO, José Julio. «Un motivo literario a la luz de La Celestina: de los libros de caballería al teatro áureo", Nueva Revista de Filología Hispánica 67.2 (2019): 473-502 [en línea, <http://dx.doi. org/10.24201/nrfh.v67i2.3527>, fecha de consulta: 02 de diciembre de 2019].

El presente estudio determina la existencia de un motivo literario no detectado hasta ahora: el contratiempo peligroso de la cita secreta nocturna de los amantes. Demuestra que su origen se encuentra en la muerte de Calisto en La Celestina. Además, establece la estructura del motivo: la cita erótica secreta y nocturna, la aparición de personajes inoportunos y la lucha consecuente. Asimismo, analiza su aparición en diversos libros de caballerías, así como en el teatro áureo (El caballero de Olmedo de Lope de Vega). Este artículo, por tanto, muestra que la influencia de los libros de caballerías va más allá de lo que normalmente se acepta y alcanza diversos géneros literarios [resumen del autor].

2670. MATOS, Kevin, «'Siempre muere y nunca acaba de morir el que ama'. Sobre la muerte del amante en algunos textos del Medioevo español», Rivista di Filologia e Letterature Ispaniche 21 (2018): 9-41 [en línea, $<$ https://riviste.edizioniets.com/rfli/index.php/rfli/article/view/185> fecha de consulta: 13 de septiembre de 2109].

Un repaso al tema de la muerte por amor en la literatura y en los tratados médicos, y a su remedio, el coito. $L C$ se utiliza como ejemplo en varias ocasiones. 
2671. MATOS, Kevin, «De Lucrecia a Melibea: la concepción del erotismo femenino en la Historia de duobus amantibus de Piccolomini y en la Tragicomedia de Calisto y Melibea de Rojas», Celestinesca 42 (2018): 189-224 [en línea, <http://parnaseo.uv.es/Celestinesca/Celestinesca42/06_Matos_Kevin.pdf>, fecha de consulta: 14 de septiembre de 2019].

La Lucrecia de la Historia de duobus amantibus de Eneas Silvio Piccolomini comparte con la protagonista rojana muchos más aspectos de los que se han identificado hasta ahora. En este trabajo se explora el proceso de amores de ambas protagonistas a fin de constatar cómo se insertan en la tradición literaria y qué novedad presentan con respecto a esta. Esto permitirá reflexionar sobre la particular concepción del erotismo femenino que presentan estas dos obras [adaptación del resumen del autor].

2672. MELIÁN, Elvira M., «De la bilis negra a la escolástica: la Celestina como arquetipo de la melancolía maléfica en el Siglo de Oro", Asclepio 70.1 (2018), 208 [en línea, <https://doi.org/10.3989/asclepio.2018.01>, fecha de consulta: 14 de septiembre de 2019].

La tensión dialéctica entre cuerpo y espíritu, derivada de su propia naturaleza dual, ha articulado el discurso de la melancolía desde sus orígenes. Como resultado encontramos distintos arquetipos bioculturales de melancolía, nacidos de la urdimbre secular entre el empirismo y las creencias del imaginario colectivo de cada sociedad. El análisis de los rasgos psicológicos y la fisonomía de la Celestina, entendida como la representación literaria de la melancolía maléfica, nos permite reconstruir el itinerario de interrelaciones entre humoralismo y escolástica medieval que moldearon esta particular «encarnación» de la misma [resumen de la autora].

2673. MESSINA FAJARDO, Trinis Antonietta, Paremiologia e traduzione: la "Celestina" e il suo repertorio paremiologico. Mantova: Universitas Studiorum, 2017.

Trabajo que estudia la notable e intrincada relación entre los refranes y las obras literarias, con especial énfasis en cómo esta se manifiesta en $L C$. Se analiza también la traducción de los refranes de la obra maestra española al italiano [adaptación del resumen de la autora].

2674. MIER PÉREZ, Laura, «Filiación celestinesca del personaje de la Farsa de la Costanza de Cristóbal de Castillejo", Bulletin of the Comediantes 69.1 (2017): 63-72 [en línea, <https://doi.org/10.1353/boc.2017.0004>, fecha de consulta: 14 de septiembre de 2019].

Este trabajo analiza cómo la vieja protagonista de la Farsa de Costanza está configurada siguiendo la tradición impuesta por Fernando de Ro- 
jas en su TCM, conservando algunas de las características más significativas del arquetipo [adaptación del resumen de la autora].

2675. MIER PÉREZ, Laura, «Reescrituras celestinescas musicales: apuntes para una historia del libreto celestinesco", Dicenda 35 (2017): 247-258. [en línea, <https://doi.org/10.5209/DICE.57710>, fecha de consulta: 14 de septiembre de 2019].

Este trabajo ofrece una visión de las adaptaciones musicales que se han hecho de la TCM bajo el formato de la ópera o del teatro musical. Analiza la adaptación de Felipe Pedrell de principios del siglo Xx y lleva a cabo un estudio de la última versión conocida, la que se está llevando a cabo en el Metropolitan Museum of Art de Nueva York de la mano de Patrick Eakin Young [adaptación del resumen de la autora].

2676. MIGUEL MARTÍNEZ, Emilio de, A, ante, bajo, cabe, con "La Celestina». Salamanca: Universidad de Salamanca, 2016.

Volumen que agrupa tanto trabajos inéditos o novedosos, como colaboraciones dispersas en revistas, capítulos de libros colectivos o material empleado en la introducción a alguna de las ediciones de $L C$ del autor.

2677. MIRANDA POZA, José Alberto, «(Re)presentaciones de la mujer en textos literarios medievales castellanos", Revista Ártemis 25.1 (2018): 60-73 [en línea, <https://doi.org/10.22478/ufpb.1807-8214.2018v25n1.41146>, fecha de consulta: 14 de septiembre de 2019].

El pensamiento de la sociedad típicamente masculina de la Edad Media (re)presenta a la mujer a partir de dos vertientes: la glorificación el amor cortés y sus derivaciones-y el rebajamiento femenino hasta extremos increíbles. Las dos posiciones convergen, en ocasiones, dentro de una misma obra, como por ejemplo en el Libro de buen amor, el género del sermón, el Arcipreste de Talavera y algunos de los exempla recogidos en el Conde Lucanor. Que la brujería y sus vínculos con Satán son algo especialmente propio de la mujer se muestra en el papel que, con relación al amor - prohibido las más de las veces- desempeñan Trotaconventos primero y más tarde la celebérrima Celestina de la $T C M$ de Rojas. Por último, la denominada «novela sentimental» nos devuelve a la glorificación de la mujer, si bien, en pleno Prerrenacimiento, a partir de parámetros humanistas, como hace Diego de San Pedro en Cárcel de amor [adaptación del resumen del autor].

2678. MITXELENA, Itziar, "El filosófico comienzo de La Celestina y la continuación de Rojas». Tesis doctoral, Universidad del País Vasco, 2018 [en línea, <http://hdl.handle.net/10810/22674>, fecha de acceso: 14 de septiembre de 2019] 
Partiendo de la tesis de la doble autoría, se estudia la parte del antiguo autor, a la que se considera una obra excepcional escrita para atacar el Naturalismo erótico. Se analiza el primer auto y se concluye que Rojas apenas se limita a repetir los patrones creados por el antiguo autor y a introducir incoherencias con respecto a su modelo [adaptación del resumen de la autora].

2679. MORALES OROZCO, Fernando A., "Influencia de La Celestina y algunos rastros del amor cortés en El caballero de Olmedo, poema dramático de Lope de Vega y Carpio", Destiempos 26 (2010): $64-76$ [en línea, <http://www.destiempos.com/n26/morales.pdf >, fecha de consulta: 25 de octubre de 2019].

El análisis se enfoca en el estudio de la presencia del amor cortés en El caballero de Olmedo y de cómo se entrelaza con algunos pasajes y personajes de $L C$ con el objetivo de señalar la diferencia entre las dos obras en cuestión que, aunque comparten un final parecido - una tragedia-, acaban siguiendo causas totalmente distintas.

2680. MYERS, Robert, "From Cairo to Camagüey: IBN Daniyal's The Shadow Spirit, Sarduy's Cobra, and Rojas's Celestina as a Bawd between the Arab World and Latin America», Comparative Literature Studies 56.2 (2019): 320-347.

Casi no hay estudios que examinen la continuidad entre las literaturas y las culturas del mundo árabe medieval y la Latinoamérica moderna a través de Al-Andalus. Mediante la crítica existente y un acercamiento derivado de la filología romance, este artículo examina la continuidad entre el teatro de sombras del poeta iraquí Ibn Daniyal, compuestas y representadas en El Cairo en torno a 1300, especialmente El espiritu de la sombra, donde aparece una alcahueta, y $L C$, de Fernando de Rojas. Se exploran los vínculos entre la obra maestra española y la novela posmoderna del cubano Severo Sarduy Cobra, publicada en 1972 , cuya protagonista es una alcahueta, y también las afinidades entre Cobra y El espíritu de la sombra. Se sugiere que estos textos y muchos otros pueden considerarse parte de una tradición multisecular y translingüística que incluye obras del mundo árabe, la Península Ibérica y Latinoamérica [adaptación del resumen del autor].

2681. NATE, Andrea, «Resurrecting the Go-Between: A Study of the Revived Bawd's Challenge to Blood Purity and Christian Doctrine in Feliciano de Silva's Segunda comedia de la Celestina», Celestinesca 42 (2018): 395-420 [en línea, <http://parnaseo.uv.es/Celestinesca/Celestinesca42/19_Nate_Andrea.pdf $>$, fecha de consulta: 14 de septiembre de 2019]. 
Este artículo defiende que la resurrección de Celestina cuestiona la noción de la pureza de sangre, así como ciertos aspectos de la doctrina cristiana que la población conversa se veía obligada a reconocer oficialmente. Compara la secuela de Silva con las escenas de resurrección en varias obras literarias medievales, así como las de ciertos textos de contemporáneos suyos. Concluye que Silva invierte el motivo de la resurrección milagrosa, utilizándolo como punto de partida no solo para continuar el argumento de $L C$, sino también para recoger varias posibles funciones de la $C C M$ y la $T C M$, especialmente la crítica social y la interrogación de varios paradigmas literarios, religiosos y culturales. Por último, propone que la secuela ayuda a entender la recepción de $L C$ y su vinculación con cuestiones de marginación social [adaptación del resumen de la autora].

2682. NAVARRO DURÁN, Rosa (ed.), Segundas Celestinas. Madrid: Fundación José Antonio de Castro, 2016.

Ediciones de las continuaciones celestinescas Segunda comedia de Celestina, de Feliciano de Silva; Tercera parte de la tragicomedia de Celestina, de Gaspar Gómez, y Tragicomedia de Lisandro y Roselia, de Sancho de Muñón.

2683. NAVARRO DURÁN, Rosa, "La desmesura de una comedia transgresora: La Segunda Celestina de Feliciano de Silva», Celestinesca 42 (2018): 375-394 [en línea, <https://parnaseo.uv.es/Celestinesca/Celestinesca42/18_Navarro_Rosa.pdf $>$, fecha de consulta: 14 de septiembre de 2019].

En este ensayo se analiza la forma literaria en que Feliciano de Silva resucita a Celestina y las consecuencias de esta resurrección. Se estudia también cómo el autor introduce otras dos novedades en su texto y la función que desempeñan en él: la relevancia de los amores de Poncia - la inteligente y discreta criada de Polandria —, y de Sigeril — paje de Felides-, y la innovación lingüística de los paréntesis de dos esclavos negros y de un pastor [adaptación del resumen de la autora].

2684. ORAZI, Veronica, «Il denaro corruttore. Ideologie e rappresentazioni. Dal Libro de buen amor alla Celestina», en Letteratura e denaro. Ideologie, metafore, rappresentazioni, ed. Alvaro Barbieri y Elisa Gregori. Padova: Esedra, 2014, 235-246.

En su segunda mitad analiza el poder corruptor del dinero en $L C$, vinculándolo especialmente a la contextualización urbana y burguesa de la obra, y destacándolo como un elemento anticortés más. Los personajes bajos se mueven por avaricia, pero esto es también un reflejo de los aspectos negativos de esa sociedad urbana y burguesa, contra la que tam- 
bién se posiciona. Para contrarrestar estas posturas negativas, $L C$ hace uso de fuentes literarias y algunos modos (amor cortés) del pasado.

2685. PADILLA CARMONA, Carlos, "Sobre algunes fonts de La Celestina», en Misogínia, religió i pensament a la literatura del món antic i la seua recepció, ed. Juan José Pomer Monferrer et al. Amsterdam: Adolf M. Hakkert, 2013, 143-153.

Explora la relación entre las fuentes clásicas de $L C$ y los personajes, el argumento y la ideología detrás de estos. Vincula el amor imposible con el mito de Píramo y Tisbe, relaciona la figura de la alcahueta con la comedia clásica y alinea ideológicamente la obra con Séneca. La menor presencia de referencias senequistas a partir del auto II se entiende como un argumento a favor de la doble autoría.

2686. PAOLINI, Devid, "Celestina e/en Italia (1500-1505)», en Literatura medieval (hispánica): nuevos enfoques metodológicos y críticos, ed. Gaetano Lalomia y Daniela Santonocito. San Millán de la Cogolla, Cilengua, 2018, pp. 339-348.

Estudio que se enfoca en la recepción de la obra maestra española en la península italiana en los primeros años del siglo XVI. Se conjetura también una posible traducción italiana de la CCM.

2687. PEDROSA, José Manuel, «Cupido, Peropalo, Plutón y san Antonio de Padua: mito, rito e iconoclastia (entre La Celestina y Lope)", eHumanista 35 (2017): 475-494 [en línea, <https://www.ehumanista.ucsb. edu/sites/secure.lsit.ucsb.edu.span.d7_eh/files/sitefiles/ehumanista/ volume35/Regular/3\%20ehum35.pedrosa.pdf >, fecha de consulta: 14 de septiembre de 2019].

El romance «Una estatua de Cupido», de Lope de Vega, describe la agresión de un amante despechado contra una estatua del dios del amor. Es un tópico vinculado a rituales populares y carnavalescos de iconoclastia, relacionados con otros seres sobrenaturales, como Plutón o san Antonio de Padua, y con episodios de obras literarias como La Celestina [resumen del autor].

2688. PÉREZ HERRANZ, Fernando Miguel, "Literatura y filosofía en el pensamiento hispano: ¿tragicomedia de Celestina o tragedia de Pleberio?», Analecta Malacitana 39.1 (2017): 9-26 [en línea, <http://dx.doi. org/10.24310/Analecta.2017.v39i1.5606>, fecha de consulta: 14 de septiembre de 2019].

Se ensaya una lectura filosófica de La Celestina en el contexto abierto por Miguel de Unamuno: el pensamiento filosófico español se encuentra diluido en la literatura, en la acción o en la mística y no en sistemas filosóficos. La Celestina muestra la imposibilidad de comuni- 
cación entre los hombres y remite al Goce como fundamento ontológico, epistemológico y ético, en claro contraste con el posterior cogito cartesiano, definido como sustancia pensante [resumen del autor].

2689. PIERA, Montserrat, "Wining and Dining at Celestina's Table in Fernando de Rojas' Tragicomedia de Calisto y Melibea», eHumanista 39 (2018): 413-428 [en línea, <https://www.ehumanista.ucsb.edu/sites/ secure.1sit.ucsb.edu.span.d7_eh/files/sitefiles/ehumanista/volume39/ ehum39.r.piera.pdf>, fecha de consulta: 14 de septiembre de 2019].

Repaso de las posibles conexiones entre el Symposium de Platón y el banquete del auto IX de LC. Examina la fusión que se produce entre, por una parte, el amor erótico y, por otra, la comida y el vino. Este banquete ofrece interesantes paralelismos con los simposia y convivia griegos y romanos, especialmente respecto al tema tratado en los diálogos en los que participan los comensales: el amor erótico. Tanto en Platón como en $L C$, el amor, como el vino, engendra imágenes ilusorias de lo que es bello y de lo amado, a menudo con trágicas consecuencias [adaptación del resumen de la autora].

2690. PIQUERAS FLORES, Manuel, "De La hija de Celestina a La ingeniosa Elena: estructura narrativa, género literario e interpolación", Edad de Oro 34 (2015): 187-200 [en línea, <http://dx.doi.org/10.15366/edadoro2015.34.012>, fecha de consulta: 14 de septiembre de 2019].

Este trabajo analiza la estructura de las dos versiones de la primera obra en prosa de Alonso de Salas Barbadillo, La hija de Celestina y La ingeniosa Elena, en relación con su posible pertenencia al género de la novela picaresca. Proponemos que el material literario añadido en $\mathrm{La}$ ingeniosa Elena -única versión autorizada por el autor- sitúa los elementos picarescos de la obra en el contexto del resto de las interpolaciones [resumen del autor].

2691. POGGI, Alfredo Ignacio, «El fin del deseo y el comienzo de la unión con Dios: Conexiones entre La Celestina y la literatura mística del siglo XVI a través del psicoanálisis», Celestinesca 42 (2018): 225-240 [en línea, $<$ http://parnaseo.uv.es/Celestinesca/Celestinesca42/07_Poggi_Alfredo.pdf>, fecha de consulta: 14 de septiembre de 2019].

Este artículo conecta la obra de Fernando de Rojas con la literatura mística española del siglo XVI y reconoce en ellas una cosmovisión compartida con respecto al deseo. En ambas visiones, los actores femeninos cobran el protagonismo en la administración del deseo y la inmanencia fragmenta el orden trascendente medieval escolástico. Además, en el espacio privado es donde se negocia el deseo y tiene un efecto concreto en el cuerpo de los participantes. Finalmente, la administración del deseo es llevada hasta las últimas consecuencias: el 
silencio, la nada y la muerte. Pero mientras que, en La Celestina, estos elementos tienen una carga negativa, los místicos lo perciben como algo positivo, el camino hacia la divinidad [resumen del autor].

2692. PRELIPCEAN, Alina-Viorela, "Hacia una nueva visión del hombre: La Celestina o uno de los momentos cumbre de la literatura universal», Journal of Romanian Literary Studies 16 (2019): 562-565 [en línea, $<$ https://old.upm.ro/jrls/JRLS-16/Rls\%2016\%2083.pdf>, fecha de consulta: 03 de diciembre de 2019].

El resumen del artículo dice querer interpretar $L C$ como una reacción al momento histórico en el que se compuso, la cual refleja la trascendencia de los cambios experimentados a finales del siglo XV (la transición de la Edad Media a la Modernidad) presentándose como una composición igualmente trascendente para la historia de la literatura, que también sufre importantes cambios a partir de entonces. Sin embargo, lo que se obtiene es un repaso rápido a algunas interpretaciones de $L C$.

2693. PRIETO DE LA IGLESIA, Remedios, y Antonio SÁNCHEZ SÁNCHEZ-SERRANO, "De nuevo sobre la ortotipografía de las Comedias de Toledo 1500 y Burgos 1499-1502 (?) y Tragicomedias de Zaragoza 1507 y Valencia 1514. Usos gráficos de h, i, y, g, j, x», Celestinesca 42 (2018): 241-268 [en línea, <http://parnaseo.uv.es/Celestinesca/Celestinesca42/08_Prieto_Remedios.pdf $>$, fecha de consulta: 14 de septiembre de 2019].

Mediante criterios cuantitativos, se estudian detenidamente los usos de las grafías h, i, y, x, g, j en función de su posición en las palabras y teniendo en cuenta las coincidencias y divergencias en las cuatro ediciones consignadas en el título. Del estudio se deducen conclusiones sobre el estado de la ortografía castellana de la época, basadas en los miles de datos extraídos de dichas ediciones, de fácil acceso para los lectores del presente estudio [resumen de los autores].

2694. PUEYO ZOCO, Víctor M., "El escándalo de La Celestina: magia y acumulación primitiva en la España del holocausto (1486-1507)», Edad de Oro 38 (2019): $35-53$ [en línea, <https://revistas.uam.es/edadoro/ article/view/edadoro2019.38.002>, fecha de consulta: 04 de diciembre de 2019].

Este artículo examina el estado de la cuestión sobre la magia y la brujería en La Celestina. Lo hace centrándose en un muy sintomático silencio: el silencio alrededor de la intervención seminal de Silvia Federici sobre el asunto en su ya clásico Calibán y la bruja, silencio que en mi opinión no desmerece el calificativo de escandaloso. Sostengo que la obra maestra de Fernando de Rojas no puede ser propiamente 
evaluada sin prestar completa y escrupulosa atención a los complejos procesos históricos que subyacen a las dinámicas de caza de brujas en la baja Edad Media. La caza de brujas no es un fenómeno religioso o incluso un fenómeno político, o (para ser más precisos) es un fenómeno religioso y un fenómeno político solo en la medida en que participa del más amplio panorama de la acumulación primitiva durante la transición del modo de producción feudal al modo de producción capitalista. Culpando obsesivamente a la Iglesia católica y a sus aparatos represivos (i.e., la Inquisición), la crítica liberal menoscaba este simple hecho. En mi cuestionamiento de esta tendencia hermenéutica, originalmente apadrinada por José Antonio Maravall en los sesenta y seguramente hegemónica hoy, muestro cómo La Celestina no puede entenderse sino como un testimonio nostálgico de la no tan lejana economía medieval del procomún [resumen del autor].

2695. RALA, Ana Laura, "Breve panorama acerca da crítica religiosa nas obras La Celestina e Lazarillo de Tormes", La Junta 1.1 (2017): 87 [en línea, <https://doi.org/10.11606/issn.2594-7753.lajunta.2017.138383>, fecha de consulta: 14 de septiembre de 2019].

Trabajo que traza un breve panorama de la crítica religiosa presente en LC y El Lazarillo de Tormes. A través de este se quiere reflejar el momento de transición que supone el paso al Renacimiento, centrándose en autores que, sin exagerar, pueden ser considerados adelantados a su tiempo por su concepción artística y por su manera de cuestionar el orden establecido [adaptación del resumen de la autora].

2696. RAMÍREZ FIGUEROA, Adán, "La construcción del pasado como estrategia de poder en La Celestina», Letras 78.2 (2018): 37-50 [en línea, <http://200.16.86.39/index.php/LET/article/view/2069>, fecha de consulta: 13 de septiembre de 2109].

A lo largo de la obra, Celestina, en los encuentros con otros personajes, remite al pasado, ya sea al propio o al de aquellos con quienes interactúa; se muestra a sí misma como un puente entre una vieja generación, representada por los padres y antiguos amos, y la nueva generación, todos aquellos que intervienen en el desarrollo de la Tragicomedia; monopoliza el conocimiento del pasado durante buena parte de la obra, situación de la que sacará ventaja para su causa. Construyendo el pasado, Celestina gana control gradual sobre aquellos que le son adversos, pues encuentra la manera de atraerlos hacia ella aprovechándose de las carencias que manifiestan y elaborando un sustituto para cada una de ellas. Será solo cuando pierda el monopolio del pasado y empiecen a intervenir otros personajes de la vieja generación cuando Celestina comience su declive. Ahora bien, esta construcción del pasado, como todas, se hace a través de la palabra y es en la pa- 
labra donde estriba el verdadero poder de Celestina; a semejanza de los magos renacentistas, Celestina controla la palabra y con ella puede modificar el desarrollo de los hechos según su voluntad. Discutir someramente el verdadero alcance de sus palabras y, en todo caso, la naturaleza misma de su poder en el desarrollo de la obra será el objetivo de este trabajo [resumen del autor].

2697. RANDAZZO, María Belén, «El imaginario social a fines del siglo XV: refranes y tópicos coincidentes en Seniloquium y La Celestina», Letras 78.2 (2019): 67-68 [en línea, <https://riviste.edizioniets.com/rfli/index. $\mathrm{php} / \mathrm{rfli} /$ article/view/190>, fecha de consulta: 04 de diciembre de 2019].

Seniloquium es un refranero castellano cuya composición es posible fechar en el último tercio del siglo XV. El manuscrito recoge casi quinientos refranes de uso corriente en la época, compilados y glosados por un clérigo versado en jurisprudencia civil y eclesiástica. La obra permaneció sin editar ni traducir de forma total hasta la primera década del 2000, cuando Fernando Cantalapiedra y Juan Moreno dan a conocer su edición crítica, que incluye la traducción íntegra de las glosas en latín. En un artículo posterior, Cantalapiedra establece el corpus de proverbios que comparten Seniloquium y La Celestina, realizando una descripción general de las paremias y los tópicos coincidentes entre ambos textos. Cantalapiedra esboza una hipótesis interpretativa según la cual los refranes han de ser entendidos como una manifestación de la lengua en uso, de modo que su recurrencia en textos contemporáneos se explica porque los mismos condensan ideas propias del imaginario social de la época. En este trabajo retomamos la línea de investigación abierta por Cantalapiedra con el objetivo de determinar cuáles son esas ideas comunes que los refranes nos permiten conocer y de qué modo son presentadas en cada obra. Asimismo, nos interesa analizar los modos de utilización de los proverbios que se desarrollan en cada texto con el propósito de consignar similitudes y diferencias en el tratamiento de los mismos, atendiendo por un lado a las glosas eruditas de Seniloquium y, por el otro, a los distintos procedimientos de inserción que se observan en La Celestina [resumen de la autora].

2698. RAVASINI, Ines, "The Expressions of Illicit Passion: Literary Disguise of Desire ('Inferno', V and La Celestina)", Rivista di Filologia e Letterature Ispaniche 21 (2019): 201-221 [en línea, <https://riviste.edizioniets.com/rfli/index.php/rfli/article/view/190>, fecha de consulta: 03 de diciembre de 2019].

El discurso sobre el amor de Francesca en el canto quinto del Infierno de Dante, lleno de alusiones intertextuales a las tradiciones de la lírica amorosa y la novela cortés, proporciona un punto de partida para analizar la manera en la que, en $L C$, Melibea expresa sus propios deseo 
y pasión ilícita. Dejando a un lado el aspecto paródico, en el uso por parte de Melibea de topoi de la tradición literaria hay un complejo proceso de imitación del código cortés, a la vez que un distanciamiento del mismo. Mientras que en la Divina comedia el episodio de Francesca nos muestra a Dante distanciándose de una tradición literaria concreta y adoptando una nueva forma de poesía, de la que la propia obra es ejemplo, en $L C$ la ambigüedad del lenguaje del amor es uno de los signos de la ruptura de los códigos tradicionales y de la forma en que son reelaborados [adaptación del resumen de la autora].

2699. RODRÍGUEZ LÓPEZ-VÁZQUEZ, Alfredo, «Sexo, eros y ficción literaria en la narrativa española del siglo Xvi: de las Celestinas a los Quijotes», Literary History. Journal of Literary Studies 158 (2016): 9-28.

Las formas literarias medievales en el tratamiento del sexo en la literatura española se basan en el uso de un lenguaje directo y naturalista. $L C$ y sus continuaciones (1534 y 1536) consagran este estilo llano, pero introducen además una retórica basada en la metáfora y la alusión. Con las dos partes del Lazarillo de Tormes se pasa a esquemas mixtos de sexo y erotismo. El relato de la conversión de la Magdalena, a fines del siglo XVI reordena el material sublimando lo erótico en una mezcla de sensualidad y juicio moral. Finalmente, Cervantes aborda la realidad del mundo de las celestinas y sus clientes ensamblando esas tres líneas literarias con un tratamiento humorístico y de crítica social y moral [adaptación del resumen del autor].

2700. ROUHI, Leyla, Mediation and Love: A Study of the Medieval Go-Between in Key Romance and Near-Eastern Texts. Leiden: Brill, 1999.

Estudio sobre la tipología de la medianera a través de textos de la Antigüedad y de la Edad Media, con especial énfasis en su papel en la poética amatoria, pero también en la literatura legal y científica. El caso de la medianera hispana medieval recibe especial atención [adaptación del resumen de la autora].

2701. ROUHI, Leyla, y Julie A. CASSIDAY, "From Nevskii Prospekt to Zoia's Apartment: Trials of the Russian Procuress», The Russian Review 58.3 (1999): 413-431 [en línea, <https://www.jstor.org/stable/2679414>, fecha de consulta: 14 de septiembre de 2019].

Comienza con una revisión de la caracterización y el tratamiento de la figura de la (y del) proxeneta en las tradiciones literarias y las legislaciones europeas occidentales a lo largo del tiempo, concluyendo que la alcahueta llega al siglo XIX como un personaje tipo completamente negativo y degradado. Contrasta esta evolución con la que tiene lugar en el contexto ruso, en el que la alcahueta también es percibida muy negativamente pero no acaba de adoptar los mismos rasgos que 
la madame de la tradición europea occidental (incluida la procedencia geográfica) hasta la europeización de Rusia en el siglo xIx. Sigue una exposición de la evolución de la valoración de proxenetas y prostitutas en la Rusia bolchevique, incluido el análisis de dos representaciones dramáticas, Proceso a una prostituta y una proxeneta (1924) y El apartamento de Zoia (1926). La primera repite el estereotipo de la alcahueta malvada, pero la segunda se desvía un tanto del modelo, presentando un personaje menos tipificado y más positivo, con el que es posible empatizar, que le sirve al autor para realizar una crítica social distinta a la perseguida en las obras moralizantes de su momento pero que no hubiese sido posible sin la vilificación previa.

2702. ROUHI, Leyla, y Julie A. CASSIDAY, "La heroica alcahueta dormía la siesta: La Celestina's Presence in La Regenta», Decimonónica 16.1 (2019): 39-51, [en línea, <http://www.decimononica.org/rouhi-cassiday>, fecha de consulta: 02 de diciembre de 2019].

Estudia posibles intertextualidades entre LC y La Regenta, destacando el uso del término "celestina" y otros relacionados con la alcahuetería, y la caracterización de determinados personajes, escenarios y situaciones, pero también desde una perspectiva psicoanalítica. Concluye que todos los personajes, en menor o mayor medida, ejercen como alcahuetes en el adulterio de la protagonista y comparten más o menos rasgos de alcahuetería o incluso con el propio personaje de Celestina, en especial, Petra, Fermín y Paula. Acaba equiparando a Ana Ozores con Melibea, siendo su caída no tanto el adulterio como la adopción de actitudes celestinescas ella misma debido a la influencia de su entorno. En este sentido, La Regenta se presenta como un retrato de una sociedad que no ha aprendido nada de los males retratados en $L C$.

2703. ŠABEC, Maja, «El enigma de la alusión a Bernardo en el primer acto de La Celestina", Colindancias: Revista de la Red de Hispanistas de Europa Central 4 (2013): 125-142 [en línea, <https://colindancias.uvt.ro/index. $\mathrm{php} /$ colindancias/article/view/14>, fecha de consulta: 14 de septiembre de 2019.

Los estudiosos alegan al menos tres posibilidades sobre la identidad del Bernardo de la diatriba de Sempronio contra las mujeres en el auto I. Algunos sostienen que se trata de San Bernardo (s. XII), en función de su supuesta duda sobre la virginidad de María. Michael Gerli sostiene que se trata de un cortesano aragonés del siglo xv, Mosén Bernard de Cabrera. Este artículo defiende una tercera posibilidad: Bernardo Gordonio (ss. XIII-XIV), autor del Lilio de medicina, con el que $L C$ tiene varias conexiones [adaptación del resumen de la autora]. 
2704. SAGUAR GARCÍA, Amaranta, "El público de las traducciones alemanas de Celestina», en Avatares y perspectivas del medievalismo ibérico, coord. Isabella Tomassetti. San Millán de la Cogolla: Cilengua, 2019, 1473-1482.

En 1520 y en 1534 veían la luz sendas traducciones al alemán de Celestina. A pesar de ser obra de un mismo autor, Christof Wirsung, se trata de dos traducciones por completo diferentes: a nivel lingüístico, a nivel ideológico, a nivel estético, a nivel material y a nivel de la teoría traductoria en que se apoyan. A partir de estas diferencias intentaremos establecer el perfil del público lector de cada una de las dos traducciones y comprobaremos si la historia de los ejemplares conocidos, conservados o no, confirma o contradice nuestro retrato. Finalmente, propondremos una explicación para la evolución del público lector de las traducciones alemanas de Celestina a lo largo del siglo XVI [resumen de la autora].

2705. SALVADOR MIGUEL, Nicasio, «Una tradición literaria acumulada durante generaciones. El territorio de La Mancha». En Debate. El porvenir de la literatura en lengua española. Madrid: Alfaguara, 1988, 55-59.

En este artículo, al hilo de las reflexiones que jalonan las distintas contribuciones de otros autores al título del libro, empiezo planteando algunas consideraciones sobre las perspectivas con que debe enfocarse el estudio del porvenir de la literatura española: el ámbito geográfico y cronológico; los sistemas y medios de comunicación y difusión; el papel de la educación y la enseñanza; las relaciones políticas y culturales entre naciones distintas. Además, como la literatura es un continuum con muchos siglos de tradición, me refiero a la vigencia que pueden tener en el futuro las grandes creaciones en español de los siglos pasados que ya han mostrado su capacidad de pervivencia, pese a contar con condiciones de difusión mucho más difíciles y precarias que las que existen hoy. Tras ofrecer diversos ejemplos, me centro en la recepción multisecular e internacional que han tenido la figura del Cid y $L C$ de Fernando de Rojas [resumen del autor].

2706. SCHMIDT, Rachel, "La cultura visual y la construcción de la tríada de mitos españoles: Celestina, Don Quijote y Don Juan», Revista Canadiense de Estudios Hispánicos 41.1 (2016): 85-111 [en línea, <https:// doi.org/10.18192/rceh.v41i1.2042>, fecha de consulta: 14 de septiembre de 2019].

Este artículo explica el proceso por el que las figuras literarias de Celestina, Don Quijote y Don Juan se han transformado en "mitos» que se consideran reflejos de la identidad española. Se examinan seis etapas comunes en la recepción de cada personaje: 1) su refundición en medios pictóricos, teatrales y musicales; 2) la simplificación visual de 
los rasgos físicos y psicológicos que definen a estos tres personajes; 3) su gran acogida internacional; 4) su recepción fuera de España como representaciones del "carácter español»; 5) la apropiación de la figura en ideologías políticas, teorías psicológicas, historias nacionales u otros sistemas explicativos de la sociedad española; y 6) la comercialización de las figuras con fines económicos. La temprana diseminación y transformación de las figuras literarias en la cultura visual fue crucial para que estas entrasen en el proceso de mitificación [adaptación del resumen de la autora].

2707. SCOTT, Rachel, Celestina and the Human Condition in Early Modern Spain and Italy. Woodbridge: Tamesis, 2017.

Aborda la lectura de $L C$ desde la perspectiva de las ideas en torno a la condición humana en el siglo xVI, con especial atención al período a partir de 1525. A través de la lectura en paralelo con cuatro obras más o menos contemporáneas -Diálogo de la dignidad del hombre de Pérez de Oliva (princeps 1546), Il cortegiano de Castiglione (princeps 1528), La vita delle puttane de Aretino (princeps 1534) y el Coloquio de las damas de Xuárez (princeps 1547) - y algunas apreciaciones sobre la historia editorial y la recepción europea de $L C$, concluye que la interpretación de la obra va mucho más allá de lo ortodoxo y lo heterodoxo, viniendo a convertirse en un reflejo de las múltiples posibilidades y contradicciones de la naturaleza humana.

2708. SERÉS, Guillermo, "Melibea, una Beatriz en el Infierno", Rivista di Filologia e Letterature Ispaniche 21 (2018): 223-242 [en línea, <https:// riviste.edizioniets.com/rfli/index.php/rfli/article/view/191>, fecha de consulta: 14 de septiembre de 2019].

De las respectivas lecturas de los libros de ficción idealista (novelas sentimentales, bizantinas, moriscas o pastoriles) las mujeres lectoras, como Melibea, pudieron interiorizar modelos novelescos que adoptaban alternativa o consecutivamente, sublimando eventualmente lo real o cotidiano. Es un tipo de lectura que creían que las dignificaba. Pero ante los casos de amor real, como el que le plantea Calisto al principio de La Celestina, no hay soluciones literarias. Calisto, enfermo de amor, recurre a la bruja Celestina para que practique un conjuro que arrebate la parte angelical de Melibea, que, una vez atrapada en las redes, bajará al «infierno» del amor humano de Calisto. Justo lo contrario de la Beatriz de Dante [resumen del autor].

2709. SIMON, Julien J., "Celestina, Heteroglossia, and Theory of Mind: The Rise of the Early-Modern Discourse», en Proceedings of the 2008 International Conference in Literature and Psychology. Lisbon: Instituto Superior de Psicologia Aplicada, 2009, 119-126. 
Analiza el diálogo de la seducción de Melibea desde la perspectiva de la Theory of Mind, una teoría del campo de las ciencias cognitivas que defiende que, en una conversación, los seres humanos intentan ponerse en el lugar (mental) del otro para entender mejor sus discursos, intenciones y sentimientos. Defiende que el éxito de Celestina depende de su capacidad para leer a su interlocutora y responder de una manera que la hace parecer extremadamente humana y real a nuestros ojos, lo que la convierte en un personaje plenamente desarrollado psicológicamente pero también evidencia el interés del autor por la psicología de los personajes. Esta inclinación sería típicamente renacentista, motivada por el lugar central concebido al ser humano en el Renacimiento. Pero también resulta relevante el concepto de heteroglosia de Bakhtin, ya que en $L C$ cada personaje tiene su voz, lo que también contribuye a la caracterización psicológica de los mismos (y a hacerlos creíbles).

2710. SIMON, Julien J., «Schema Theory, Prototype Theory, and the Novela Dialogada: Toward a Perspectivist and Dynamic View of Literary Genres», Laberinto: An Electronic Journal of Early Modern Hispanic Literatures and Culture 7 (2014): 64-90 [en línea, <https://acmrs.org/sites/ default/files/v7_Laberinto_Simon.pdf $>$, fecha de consulta: 14 de septiembre de 2019].

Partiendo de la base de que $L C$ es una novela dialogada, se pasa a describir la problemática de la delimitación genérica en literatura y se pregunta si la teoría cognitiva podría arrojar luz sobre los procesos que llevan a la diferenciación genérica. Se señala que la crítica literaria ha intentado resolver esta cuestión haciendo uno de los paradigmas psicológicos de la Schema Theory y la Prototype Theory, pero sin pararse a explorar cómo las relaciones entre ambas pueden explicar nuestra manera de percibir el género literario mejor que su uso conjunto o por separado. Tras presentar los dos paradigmas y explicar cómo se relacionan entre ellos, se propone un modelo cognitivo combinado, que luego se aplica al caso particular de la novela dialogada $y$, en particular, a $L C$. En esencia, se la ubica entre los géneros de la novela y el drama, pero en el radio de acción de ambos y en su zona de interesección (partiendo de la representación del género literario como una estructura radial organizada en torno a un núcleo, que sería el prototipo, y en la que a mayor distancia del núcleo se percibe menor pureza genérica). Sin embargo, puesto que tanto la percepción del género propiamente dicho como de los géneros no tan evidentes evoluciona con el paso del tiempo, la percepción de la novela dialogada también varía. En consecuencia, al final la percepción del género, no solo en el caso de la novela dialogada, sino en cualquier situación, depende de la perspectiva del estudioso, por lo que la decisión final 
al respecto tiene más que ver con el individuo y su contexto que con nada inherente a las obras. Por último, se propone clasificar $L C$ como obra transgenérica.

2711. SIMON, Julien J., "Psychologizing Literary Characters in Fernando de Rojas' Celestina: The Emergence of Mind in Early Modern Spanish Literature", en Self, Other, and Context in Early Modern Spain: Studies in Honor of Howard Mancing, eds. Isabel Jaén et al. Newark: Juan de la Cuesta, 2017, 43-56.

Los personajes de $L C$ intentan leer las creencias, las intenciones, los deseos y las expectativas de sus interlocutores cuando dialogan, adaptando su discurso a lo que creen extraer de ellos. Este comportamiento coincide con la teoría cognitiva moderna de la Theory of Mind, pero también apoya las ideas de Bakhtin sobre el origen del discurso novelístico. El argumento y el análisis son los mismos que en el artículo de arriba ("Celestina, Heteroglossia, and Theory of Mind...») pero la estructura es más clara y la conclusión es que Bakhtin debería haber incluido $L C$ en sus estudios sobre el desarrollo del discurso novelístico.

2712. SIMON, Julien J., "A Wild Fable: Affect and Reception of Fernando de Rojas' Celestina (1499)», en The Palgrave Handbook of Affect Studies and Textual Criticism, ed. Donald R. Wehrs y Thomas Blake. New York: Palgrave MacMillan, 2017, 609-625 [en línea, <https://doi. org/10.1007/978-3-319-63303-9_22>, fecha de consulta: 03 de diciembre de 2019].

$L C$ es uno de los primeros libros de ficción en prosa escritos en español después de la adopción de la imprenta manual. La historia de la literatura española considera $L C$ el texto más influyente después del Quijote, tanto por su valía literaria como por su éxito editorial en España y en Europa. En este trabajo se explora cómo LC y el personaje homónimo lograron conmover a sus lectores hasta el punto de convertirse en una de las obras literarias más exitosas de la temprana Modernidad. Se identifica, asimismo, dos tipos de lectores de $L C$ : primero, el público objetivo original, una comunidad de lectores cultos y humanistas, conformada principalmente por estudiantes de la Universidad de Salamanca, y, segundo, un público mayor de lectores legos, que consagraron el éxito de la obra. Mediante la combinación de aspectos socio-histórico-literarios de la recepción de $L C$ con los resultados de las investigaciones sobre los mecanismos cognitivos y afectivos en marcha durante la lectura de ficción, este trabajo arroja una nueva mirada a la historia de la recepción de la obra, a la vez que pone de manifiesto cómo el estudio de la mente de aquellos siglos nos ofrece un retrato más completo e integrado de la cognición y la cultura temprano modernas [adaptación del resumen del autor]. 
2713. SNOW, Joseph Thomas, "Readers Reading/Writing: Celestina, 1498-1526», Estudios Hispánicos 37 (2005), pp. 245-256.

La complejidad de la transmisión del texto de $L C$ en sus primeros años (1496-1526), antes de estabilizarse en los años siguientes, sirve para, mediante la observación de sus diferentes estados, conocer las relaciones entre los autores que desempeñaron algún papel en la historia del texto. Primero, como lectores, y, después, como escritores. Lo que este estudio revela es que un número sorprendente de lectores contribuyó a la carrera comercial por ganar lectores con nuevo material impreso [adaptación del resumen del autor].

2714. SNOW, Joseph Thomas, "Todo sobre Lucrecia», Letras 77.1 (2018): 19-34 [en línea, <http://erevistas.uca.edu.ar/index.php/LET/article/ view/1709>, fecha de consulta: 14 de septiembre de 2019].

Esta nueva aproximación al tema de la caracterización en la TCM parte de mi percepción de las intenciones de sus autores. Lucrecia es su tema. Como la criada de Melibea, ha despertado poco interés en generaciones de lectores. Creo, por el contrario, que como la compañera constante de Melibea en cada paso de sus relaciones ilícitas con Calisto, pero decidida a no revelar esta información a sus patrones Pleberio y Alisa, Lucrecia actúa como una importante clave para entender las consecuentes tragedias. Otro aspecto que se destaca es el despertar en Lucrecia - por ser testigo de tantas noches de amor apasionado- del reconocimiento de su propia sexualidad [resumen del autor].

2715. SNOW, Joseph Thomas, "El mundo celestinesco que vivió Feliciano de Silva y que nutrió su Segunda Celestina (1534)», Celestinesca 42 (2018): 323-338 [en línea, <http://parnaseo.uv.es/Celestinesca/Celestinesca42/16_Snow_Joseph.pdf>, fecha de consulta: 14 de septiembre de 2019].

A lo largo de su carrera como autor, Feliciano de Silva (1491-1554) publicó varios libros de caballería y solo una obra celestinesca, Segunda Celestina, en 1534. Varios estudios han comparado su obra con la obra original, la Tragicomedia de Calisto y Melibea (TCM). En este artículo, consideramos las otras obras celestinescas en distintos géneros (poesía, teatro y prosa) que se produjeron entre 1513 y 1534 que pudieron haber tenido una influencia, entre las muchas diferencias, de su obra con la TCM [resumen del autor].

2716. SNOW, Joseph Thomas, "La cuestión peliaguda del tiempo en Celestina: propuesta de acotaciones escénicas», Celestinesca 42 (2018): 269 290 [en línea, <http://parnaseo.uv.es/Celestinesca/Celestinesca42/09_ Snow_Pepe.pdf $>$, fecha de consulta: 14 de septiembre de 2019]. 
En una obra dialogada de veintiún actos, los personajes ocasionalmente aluden explícitamente al tiempo que pasa. No obstante, se puede deducir que hay un tiempo implícito que, sin estar anotado textualmente, transcurre también entre los eventos de la obra. En la Tragicomedia de Calisto y Melibea estos casos del tiempo que pasa "en off» se pueden reconstruir leyendo con detenimiento los diálogos de los distintos personajes. En una edición moderna, se podría agregar unas acotaciones que aclararían el tiempo que pasa y mejorar la experiencia del lector. Efectivamente, casi tres semanas de tiempo pasa en la obra, independiente del mes que los autores agregaron para extender los amores de los protagonistas titulares [resumen del autor].

2717. STAHL, Andrea, "Von Bewertungen zu Interaktionen: Stimmung und Denken in Grimalte y Gradissa (1495) und La Celestina o Tragicomedia de Calisto y Melibea (1499)", Philologie im Netz 14.5 (2018), s.p. [en línea, <http://web.fu-berlin.de/phin/beiheft14/b14t02.pdf $>$, fecha de consulta: 03 de diciembre de 2019].

En dos ejemplos tempranos de la novela sentimental española, la exposición abierta del estado anímico viene acompañada de una serie de procesos de pensamiento que cada vez adquieren una forma más concreta y que evidencian una organización efectiva de las formas de conocimiento. En Grimalte y Gradissa (1495) la mención de los estados anímicos solamente aparece en relación a procesos de (auto)evaluación, mientras que en $L C$ (1499) lo hace vinculada a una necesidad de interacción humana cada vez mayor. Puesto que los estados anímicos unidos a procesos de pensamiento desempeñan numerosas funciones de mediación en ambas obras, evidencian que las relaciones entre individuos, el mundo y su contexto se están volviendo frágiles en el paso a la Modernidad [adaptación del resumen de la autora].

2718. TEKIN, Burcu, "Ortaçağ İspanya 'sinda Büyü, Büyücülük Ve La Celestina Adli Esere Yansimasi (Spells and Sorcery in Medieval Spain and Their Reflection to La Celestina)", Ankara Universitesi Dil ve TarihCoğrafya Fakültesi Dergisi 55.1 (2017): 305-324 [en línea, <http://dtcfdergisi.ankara.edu.tr/index.php/dtcf/article/view/574>, fecha de consulta: 14 de septiembre de 2019].

Este artículo discute a grandes rasgos la relevancia de la magia, la hechicería y la brujería y su papel en la Antigüedad y la Edad Media, con especial énfasis en la España del siglo XV. Tras una introducción a este tema, estudia el reflejo del mismo en $L C$ [adaptación del resumen de la autora].

2719. TORREGROSA DÍAZ, José Antonio, "Tragicomedia de Calisto y Melibea». Anotaciones críticas y textuales y versión modernizada. Tesis 
Doctoral, Universidad de Murcia, 2015 [en línea, <https://digitum. um.es/xmlui/handle/10201/44586>, fecha de consulta: 14 de septiembre de 2019].

Partiendo de la edición de Lobera et al., se hace un recorrido por los veintiún actos del texto celestinesco (y también por los llamados paratextos) para analizar y explicar una multitud de pasajes de la obra que aún hoy presentan problemas de fijación textual o de comprensión. A las notas resultantes, les acompaña una versión actualizada de la TCM pensada para acercar la obra a lectores que no poseen preparación filológica [adaptación del resumen del autor].

2720. TORREGROSA DÍAZ, José Antonio, ed., La Celestina (Tragicomedia de Calisto y Melibea). Madrid: Anaya, 2017.

Edición modernizada del texto, fruto de la tesis doctoral del autor.

2721. TORREMOCHA HERNÁNDEZ, Margarita (2015), «De La Celestina al alcahuete: del modelo literario a la realidad procesal», Tiempos Modernos 8.30, s.p. [en línea, <http://www.tiemposmodernos.org/ tm3/index.php/tm/article/view/375/453>, fecha de consulta: 03 de diciembre de 2019].

El proxeneta tiene en la literatura del Siglo de Oro español un modelo en la Celestina y las obras celestinescas. Ello ha permitido crear un arquetipo, que desde la ficción se ha generalizado y convertido en marco en el que representar una actividad económica, que en la realidad social de la época Moderna, se definía por patrones diferentes. Dedicamos este estudio al análisis de las diferencias de la alcahuetería entre el mundo literario y real, a través del análisis de pleitos criminales, y a la definición del modus operandi de terceras, rufianes, consentidores y alcahuetas [resumen de la autora].

2722. UGARTE I BALLESTER, Xus, «Llicències paremiològiques (i altres) dels tres torsimanys catalans de Franklin, Rojas i Rabelais: Gaietà Vidal 1868, Antoni Bulbena 1914 i Lluís Faraudo 1929», Anuari de Filologia: Estudis de Lingüística 5 (2015): 141-158 [en línea, <http://revistes. ub.edu/index.php/AFEL/article/view/AFEL.2015.5.9>, fecha de consulta: 14 de septiembre de 2019].

Estudia las estrategias traductológicas del traductor de $L C$ al catalán, Antoni Bulbena, quien se enfrenta a los 383 refranes de la TCM [adaptación del resumen de la autora].

2723. VALERO MORENO, Juan Miguel, «Dante in La Celestina: Conflicts or Textual contiendas", Rivista di Filologia e Letterature Ispaniche 21 (2019): 243-283 [en línea, <https://riviste.edizioniets.com/rfli/index.php/rfli/ article/view/192>, fecha de consulta: 03 de diciembre de 2019]. 
En este artículo se valora la presencia de Dante en $L C$. Para explicar esta presencia, se proponen caminos alternativos a la identificación de influencias textuales directas para centrarse en su lugar en los modelos literarios e interpretativos que pueden remontarse a una meditatio sobre Dante. Este análisis se basa en la difusión de Dante en la Península Ibérica durante el siglo xv, su confluencia con el estudio de Virgilio y Séneca y la apropiación de estos por parte de la poesía culta y la ética vernacular castellanas. Este recorrido finaliza con una lectura en paralelo de la traducción castellana de la Medea de Séneca y el conjuro infernal del auto tercero de $L C$. Así se muestra la cultura literaria del primer autor y de Fernando de Rojas que, a la luz de este estudio, estaría firmemente arraigada en las convenciones y los experimentos textuales de la segunda mitad del siglo xv, que sirve para dar la fuerza que caracteriza al texto [adaptación del resumen del autor].

2724. VÁZQUEZ CRUZ, Adam A., "Ars memorativa, abejas y miel en La Celestina», Nueva Revista de Filología Hispánica 66.2 (2018): 529-553 [en línea, <http://dx.doi.org/10.24201/nrfh.v66i2.3426>, fecha de consulta: 14 de septiembre de 2019].

En este artículo se analiza el texto celestinesco desde la perspectiva del arte de la memoria. Gracias a la caracterización de la alcahueta como abeja y de los amantes como flores, se abre una posibilidad interpretativa que echa mano de una analogía ampliamente usada para describir los procesos intelectivos. Esta descansa en una comparación entre los procesos para elaborar miel y para generar discurso. Celestina, por medio de la palabra, manipulará a los personajes, pero su falta de prudencia la llevará a la muerte. Este artículo pretende ampliar nuestro entendimiento de $L C$ al explorar una de las tradiciones que evoca [resumen del autor].

2725. VILLA, Juan Diego, "Aquella ministra de el demonio, Celestina': el fantasma de Celestina en la manualística de sujeción femenina del siglo XVI», Texturas 6 (2006): 129-141 [en línea, <https://doi. org/10.14409/texturas.v1i6.2849>, fecha de consulta: 14 de septiembre de 2019].

El presente estudio se centra en el legado de $L C$ en el Siglo de Oro español, momento histórico que consagra a la obra de Rojas como un best-seller indiscutido del período y que permite retomar — desde la perspectiva de la consagración lectora - las muy opinables categorizaciones que se han formulado de esta obra y del conjunto denominado "celestinesca». De entre los múltiples testimonios, indicadores en gran medida del respeto y tributo brindado por los ingenios del Xvi y del xVII, esta lectura se concentra en la peculiar recepción que realiza un manual de educación femenina en el cual la figura de la protago- 
nista resulta actualizada como norte vitando por toda familia preocupada por la sana educación de sus hijas [resumen del autor].

2726. VILCHIS FRAUSTRO, José Carlos, «Pármeno envenenado: sexo y traición en La Celestina», Destiempos 56 (2017): 7-34 [en línea, <http:// www.destiempos.com/56/vilchis.pdf $>$, fecha de consulta: 14 de septiembre de 2019].

Explora la corrupción de Pármeno tratándolo como un proceso de envenenamiento iniciado por la conversación con Celestina y culminado por la intervención de Areúsa. Tras discutir el carácter de Pármeno, poniendo en duda su natural bondadoso y explorando la posibilidad de que ya contenga una inclinación hacia el mal, se centra en el papel de la mujer en la corrupción de Pármeno y en lo que la imagen de la «mujer venenosa» medieval (venenosa, sobre todo, a causa de la sangre menstrual) puede aportar a la interpretación de $L C$. Frente a la tradición, el efecto del veneno en Pármeno será de tipo moral, no físico, pero igualmente lo conducirá a la muerte.

2727. XIAO, Yang, «Las similitudes y diferencias entre los inicios del teatro español y del teatro chino", Sinología Hispánica 1.1 (2015): 145-172 [en línea, <http://dx.doi.org/10.18002/sin.v1i1.5187>, fecha de consulta: 14 de septiembre de 2019].

Análisis de los orígenes del teatro español en paralelo con el teatro chino temprano. El objetivo es proporcionar una comprensión más amplia de las características históricas y temáticas de los teatros de las dos culturas. Entra las obras analizadas aparece también $L C$ [adaptación del resumen del autor].

2728. XIAO, Yang, «El fondo familiar y cultural de los padres de Melibea y Cui Yingying", Romance Studies 36.4, (2018): 139-150 [en línea, $<$ https://doi.org/10.1080/02639904.2018.1546812>, fecha de consulta: 14 de septiembre de 2019].

Comparación entre Alisa y Pleberio, en LC, y Zheng Shi, en Historia del ala oeste. Observa tanto las maneras y actitudes que toman los padres al ejercer la tutela de sus hijas, como los papeles que juegan en las respectivas historias amorosas de esas dos jóvenes muchachas. Alisa y Pleberio se caracterizan por la negligencia y la ignorancia. A diferencia de los padres de Melibea, Zheng Shi, madre de Cui Yingying, se distingue por la prudencia y el cuidado al ejercer la tutela de su hija. Por otra parte, en las dos obras los padres han propuesto a su hija un matrimonio con un muchacho noble, pero las muchachas los consideran obstáculos para su libre albedrío y para consumar el amor con sus enamorados [adaptación del resumen del autor]. 
2729. XIAO, Yang, Tematología comparada de la concepción del amor en dos literaturas tradicionales: "La Celestina» e "Historia del ala oeste». Vigo: Academia del Hispanismo, 2018.

Aunque es imposible que se influyeran entre sí, LC e Historia del ala oeste tienen muchas similitudes. Ambas son dramas que se han desarrollado a partir de una o varias obras que ya estaban escritas. Su autoría es polémica y problemática. Sus protagonistas están arrebatados por la pasión y muestran unos comportamientos amorosos similares, desde el primer encuentro hasta el acto sexual. Otras coincidencias son elementos más o menos universales: la casamentera o intermediaria del amor entre los protagonistas, los padres que proponen un marido para casar a su hija, los huertos y el jardín como espacios literarios característicos para el amor, las prendas de amor... [adaptación del resumen del autor].

2730. XIAO, Yang, "The Love of Medieval Women Who Walked out of the 'Room': Taking Melibea, the Heroine of La Celestina, as an Example», en The Proceedings of 2019 Youth Academic Forum on Linguistic, Literature, Translation and Culture (May 24-25, 2019, Hangzhou, China), ed. Le Cheng et al. The American Scholars Press, 2019, 108-112.

El término «espacio» del título se refiere a la visión del amor femenino en la Edad Media. Mediante la descripción dramática de la heroína de $L C$, quien rompe con la mundanalidad religiosa y feudal sin importarle el honor de su familia y su dignidad personal, Melibea persigue la descripción dramática de la naturaleza humana. No solo hace evidente que el estatus de hombres y mujeres en la Edad Media no es el mismo, sino que el amor de las mujeres no puede ser libremente expresado, por lo que siente la imperiosa necesidad de abandonar ese espacio en el que se le ha recluido para satisfacer el deseo humano. A la vez, pone de evidencia que la resistencia al amor cortés y al matrimonio social está cediendo el paso al amor natural y el matrimonio por amor. En consecuencia, se está acabando con la situación tradicional en la que la escritura está dominada por los hombres, dando más voz y autoridad a las mujeres [adaptación del resumen del autor].

2731. YURI PORRAS, George, "El mal de amores y las canciones en las primeras dos Celestinas», Confluencia 24.1 (2008): 139-151 [en línea, <https://www.jstor.org/stable/27923325>, fecha de consulta: 14 de septiembre de 2019].

Calisto y Melibea manifiestan las características típicas del «mal de amores", morbus amoris o amor hereos, que afectan específicamente a jóvenes nobles y ricos. En LC y su continuación, la Segunda Celestina de Feliciano de Silva, el mal de amores afecta también a la plebe, aunque 
en este caso es llamado nimis amor, "amor excesivo" o "amor mágico», $y$ es causado por algún maleficio. En este trabajo se estudian, primero, el fuerte paralelismo entre la música y el mal de amores y, segundo, las funciones contrapuestas de la música como cura y causa de la enfermedad fisiátrica de los personajes en ambas Celestinas [adaptación del resumen del autor].

2732. ZUBIETA, Mar, ed., "Celestina" de Fernando de Rojas. Madrid: Ministerio de Educación, Cultura y Deporte, Secretaría de Estado de Cultura, 2016 [en línea, <http://teatroclasico.mcu.es/wp-content/ uploads/2016/04/pedagogico_CELESTINA-web.pdf>, fecha de consulta: 13 de septiembre de 2019].

Número 55 de los Cuadernos Pedagógicos de la Compañía Nacional de Teatro Clásico. Incluye una breve introducción a $L C$ y detalles sobre el montaje de José Luis Gómez. 
